\title{
‡USGS
}

\section{Effect of Baseline Corrections on Response Spectra for Two \\ Recordings of the 1999 \\ Chi-Chi, Taiwan, Earthquake}

by D.M. Boore ${ }^{1}$

Open-File Report 99-545, Version 1.0

1999

This report is preliminary and has not been reviewed for conformity with U.S. Geological Survey editorial standards or with the North American Stratigraphic Code. Any use of trade, product, or firm names is for descriptive purposes only and does not imply endorsement by the U.S. Government.

\section{U.S. DEPARTMENT OF THE INTERIOR}

\section{U.S. GEOLOGICAL SURVEY}

${ }^{1} 345$ Middlefield Road, Menlo Park, CA 94025 


\section{Introduction}

Displacements derived from the accelerogram recordings of the 1999 Chi-Chi, Taiwan earthquake at stations TCU078 and TCU129 show drifts when only a simple baseline derived from the pre-event portion of the record is removed from the records. The appearance of the velocity and displacement records suggests that changes in the zero-level of the acceleration are responsible for these drifts. The source of the shifts in zero-level are unknown, but might include tilts in the instruments or the response of the instruments to strong shaking. This note illustrates the effect on the velocity, displacement, and response spectra of several schemes for accounting for these baseline shifts. The most important conclusion for earthquake engineering purposes is that the response spectra for periods less than about $20 \mathrm{sec}$ are unaffected by the baseline correction. The results suggest, however, that static displacements estimated from the instruments should be used with caution. Although limited to the analysis of only two recordings, the results may have more general significance both for the many other recordings of this earthquake and for data that will be obtained in the future from similar high-quality accelerograph networks now being installed or soon to be installed in many parts of the world.

\section{Evidence of Baseline Shifts}

The digital accelerograph installed and maintained by Central Weather Bureau in Taiwan produced a rich set of records from the September 20, $1999 \mathbf{M}=7.6$ Chi-Chi, Taiwan earthquake and its aftershocks (Shin et al., 2000). This earthquake has produced the most complete set of strong-motion recordings ever obtained. The data were obtained from Teledyne Geotech Model A900 digital accelerographs, with \pm 2 g gain and 16-bit resolution, recorded at 200 samples per second. The transducers are flat to acceleration from dc to $50 \mathrm{~Hz}$.

The system uses a trigger algorithm and a buffer so that the pre-trigger part of the ground motion is preserved. At this time data from only two stations have been released (Lee, 1999), but the features found in the analysis of these records are probably not restricted 
to those records.

The stations for which data have been released are TCU078 and TCU129. These stations are within $10 \mathrm{~km}$ of the earthquake epicenter (Figure 1).

The first processing applied to the data was to reformat the data into the file format used by the program BAP (Basic Accelerogram Processing, Converse, 1984) and then use BAP to remove a baseline obtained from the average of the pre-event portion of the record and to obtain velocity and displacement time series by integration of the baseline-corrected accelerations. Figures 2 and 3 show the accelerations and displacements, respectively, for the three components of motion at the two stations. The displacements show no signs of leveling off at the end of the recorded duration, and for the horizontal components at station TCU129 are both unrealistically large (in excess of $15 \mathrm{~m}$ ) and are quadratically rather than linearly increasing with time, unlike the other recordings. Given the large offsets across the surface exposure of the faulting (as much as $8 \mathrm{~m}$, http://www.rcep.dpri.kyotou.ac.jp/main/taiwan/summary-E.html), and ground movements from GPS stations in the epicentral area of about $340 \mathrm{~cm}$ and $180 \mathrm{~cm}$ horizontal and vertical motion, respectively (http://www.sinica.edu.tw/ jclee/921chichi_geodesy.htm), the maximum displacements on the other components cannot be dismissed out of hand. The nature of the waveforms and the large displacements on the horizontal components of TCU129 strongly suggest, however, that the displacement traces do not represent the true displacement of the ground.

The steps in processing are illustrated in Figure 4 for the E-W component of station TCU129. The top trace is the recorded trace, with about $20 \mathrm{~s}$ of pre-event memory and about 90 s of recording. A small, approximately constant dc offset is present on this trace. This dc component is $11.85 \mathrm{~cm} / \mathrm{s}^{2}$, as obtained by averaging the first $18 \mathrm{~s}$ of data. The second trace shows the acceleration after removing this baseline component from the whole record, and the third and fourth traces show the velocity and displacement traces obtained by single and double integration of the baseline-corrected acceleration.

A reasonable constraint on any ground motion recording is that the ground velocity should be essentially zero after the strong shaking has ceased. This is clearly not the case for 
the E-W component of the motion at TCU129 (and although not shown, for the other components of motion at TCU129 and TCU078 as well), and the almost linear trend in velocity is a direct indication that the baseline of the acceleration for at least the last half of the record is not the same as that from the pre-event portion of the record. The difference need not be large to produce the observed slope in the velocity and the large final displacement. As will be discussed in the next section, a straight line fit to the last $30 \mathrm{~s}$ of the velocity has a slope of $-1.305 \mathrm{~cm} / \mathrm{s}^{2}$; this is a direct measure of the difference in acceleration baselines, and is much smaller than the baseline of $11.85 \mathrm{~cm} / \mathrm{s}^{2}$ determined from the pre-event portion of the record. The displacement at a time $t$ after a step in

acceleration of $\delta a$ is $0.5 \delta a t^{2}$. For $\delta a=1.3 \mathrm{~cm} / \mathrm{s}^{2}$ this gives $1600 \mathrm{~cm} / \mathrm{s}^{2}$ after $50 \mathrm{~s}$ - a small shift in acceleration baseline will have a profound effect on the final displacement. The next section considers several ways of correcting for changes in the acceleration baseline.

\section{Some Methods for Correcting Baseline Shifts}

Six methods for baseline correction were used. For illustration, in this section the methods were applied only to the E-W component of the recording at station TCU129. This component is the worst case in that it has the largest final offset when only the simplest correction scheme is used (Figure 3). All traces were corrected using five of the six methods, and response spectra, presented in the next section, were computed for the corresponding baseline-corrected accelerations.

The correction schemes are as follows:

1) Remove average of pre-event portion. This is a necessary correction and was used as an initial correction to the acceleration traces for which the other baseline corrections were applied. Because it does not attempt to correct for baseline changes subsequent to the onset of shaking, this correction could be said to represent the case of no baseline correction.

2) Remove straight line fit to acceleration trace. A line was fit to the acceleration trace between the onset of shaking and the end of the record. This line was removed from the 
acceleration, beginning at the onset of shaking.

3) Acausal low-cut filter of trace corrected in step 2. The standard accelerogram processing of strong-motion data by the program BAP uses an acausal Butterworth filter. This filter, with an order of 2 and a corner of $0.05 \mathrm{~Hz}$, was applied to the trace obtained from the baseline-correction scheme in step 2 . The response of the acausal filter is $1 /\left(1+(0.05 / f)^{4}\right)$.

4) Causal low-cut filter of trace corrected in step 2. The acausal filter used in scheme 3) produces a large pre-event filter transient and can reduce the peak displacement compared to using a causal filter. For this reason, I processed the data using a 2nd order causal Butterworth filter with corner frequency of $0.05 \mathrm{~Hz}$. The response of the causal filter is $1 / \sqrt{1+(0.05 / f)^{4}}$.

5) Iwan et al. (1985), Option 1. This and the next scheme were proposed in a paper by Iwan et al. (1985). In processing digital records, they observed drifts in the velocity and displacement records similar to those shown in Figure 4. For the instruments that they were testing, they attributed the source of the baseline shift to a hysteresis in the transducer that occurred when acceleration exceeded about $50 \mathrm{~cm} / \mathrm{s}^{2}$. The consequence was that the baseline shift during the strong motion could be different than that following the strong motion, and therefore a correction scheme involving two steps in acceleration was proposed. This procedure is as follows:

(a) A straight line given by the equation

$$
v_{f}(t)=v_{0}+a_{f} t
$$

is fit to the part of the velocity trace following the strong shaking.

(b) The step in acceleration $a_{f}$ is removed from the latter part of the acceleration trace, starting from a time $t_{2}$ defined as the last time the acceleration exceeds $50 \mathrm{~cm} / \mathrm{s}^{2}$.

(c) A different acceleration step, $a_{m}$, is removed from the uncorrected acceleration between the onset of shaking exceeding $50 \mathrm{~cm} / \mathrm{s}^{2}$ (this time is $t_{1}$ ) and time $t_{2}$. The size of the correction $a_{m}$ is determined by the requirement that the final velocity, after 
baseline correction, average to zero. This is satisfied if the velocity of the baseline correction at the end of the segment, $a_{m}\left(t_{2}-t_{1}\right)$, equals the velocity from the fitted line, $v_{f}\left(t_{2}\right)$. This gives the equation

$$
a_{m}=\frac{v_{f}\left(t_{2}\right)}{\left(t_{2}-t_{1}\right)} .
$$

Figures 5, 6, and 7 show the corrections for acceleration, velocity, and displacement, respectively. The curves shown in those figures are the actual ones used in applying Iwan et al.'s option 1 correction to the E-W component recording at station TCU129.

6) Iwan et al. (1985), Option 2. The time $t_{2}$ in option 1 was based on some understanding of the physical basis for the baseline shifts. The two-baseline-shift correction scheme can be used, however, with any value of $t_{2}$ between $t_{1}$ and the end of the record, $t_{f}$, and still satisfy the requirement that the average of the final corrected velocity be zero. If $t_{2}$ is free to float between $t_{1}$ and $t_{f}$, the final displacement derived from the corrected acceleration can have a wide range of values. This is shown in Figure 8, which shows the final displacement of the E-W recording at TCU129 for the allowable range of $t_{2}$; the range is from $-118 \mathrm{~cm}$ to $+541 \mathrm{~cm}$. Iwan et al. (1985) propose that $t_{2}$ be chosen so as to minimize the final corrected displacement; they call this "Option 2". In figure 8 it corresponds to $t_{2}=33.07 \mathrm{~s}$, the point at which the corrected displacement is zero (the final displacement cannot always be made zero by an appropriate choice of $t$; for the N-S and E-W components of motion at station TCU078 the minimum displacements are 63 and $90 \mathrm{~cm}$, respectively). It is easy to show that the value of $t_{2}$ corresponding to the minimum corrected displacement is given by

$$
t_{2}=\frac{\left(2 v_{0} t_{f}+a_{f} t_{f}^{2}-v_{0} t_{1}\right)-2 D_{o b s}}{\left(v_{0}+a_{f} t_{1}\right)},
$$

where $D_{o b s}$ is the final displacement from the uncorrected acceleration time series. The final displacement $D_{\text {corr }}$ of the corrected acceleration time series is given by

$$
D_{\text {corr }}=D_{o b s}-\left(0.5 v_{f}\left(t_{2}\right)\left(t_{2}-t_{1}\right)+v_{f}\left(t_{2}\right)\left(t_{f}-t_{2}\right)+0.5 a_{f}\left(t_{f}-t_{2}\right)^{2}\right),
$$

where $v_{f}$ is given by equation (1). 
The results of applying these various baseline-correction schemes are displayed in Figure 9, 10, and 11. Figures 9 and 10 give the velocities and displacements derived from the corrected accelerations. In these figures each trace is scaled individually, so the relative maxima must be obtained from the labels of the ordinate. The peak velocities are relatively stable, ranging between 53 and $73 \mathrm{~cm} / \mathrm{s}$. The peak displacements have a much wider range, from 45 to $1924 \mathrm{~cm} / \mathrm{s}$, and the waveforms have more variation than do those of the velocity traces. To better illustrate the relative amplitudes for the displacements, Figure 11 is an overlay of the six displacement traces. It is clear that there is a wide range in waveforms for the displacement traces.

For completeness, Figures 12-21 show the velocities and displacements for the other components at station TCU129 and all of the components at station TCU078.

The difference in character of the velocity and displacement traces shown in Figures 9 21 is an indication that the baseline-correction schemes are most important for the longer periods components of the records. This is not a surprising observation; I do a more quantitative comparison of the relative long period content in the next section.

\section{Effect on Response Spectra of Baseline Corrections}

Some idea of the effect of a step in acceleration on response spectra is given by the response of an oscillator to a step $a_{b l}$ in acceleration. From equation (A4b) this is

$$
\left|u_{\max }\right|=a_{b l} T^{2} \frac{\left(1+\exp \left(-\eta \pi / \sqrt{1-\eta^{2}}\right)\right)}{4 \pi^{2}}
$$

where $T$ and $\eta$ are the undamped natural period and the fractional damping an oscillator. Although the response spectrum of the sum of two time series (the baseline offset and the ground acceleration in our case) is not the sum of the individual response spectra, the response of the baseline shift alone gives an upper bound to the effect of a step in acceleration. With $a_{b l}=1 \mathrm{~cm} / \mathrm{s}^{2}$ and $\eta=0.05$,

$$
u_{\max }=0.047 T^{2}
$$


Because of the strong dependence on period, the effect of a step in acceleration will be much more important at long periods than at short periods. For a period of $1 \mathrm{~s}$, the response is only $0.05 \mathrm{~cm}$, whereas at $20 \mathrm{~s}$ the response is $19 \mathrm{~cm}$.

From the analysis above, I would expect that uncertainties in response spectra due to unknown baseline shifts of the order of $1 \mathrm{~cm} / \mathrm{s}^{2}$ will be unimportant at periods of engineering interest. This can be shown directly by comparing the displacement response spectra for the time series derived from each of the baseline-correction schemes mentioned earlier. I have done this for each component recorded at each station. In order to evaluate the response to periods out to $100 \mathrm{~s}$, I wrote a program that extends the time series with zeros if need be to capture the peak response of the oscillator. The results are shown in Figure 22 through 27. These comparisons show that the response spectra are not affected by the baseline-correction schemes for periods less than about $20 \mathrm{~s}$. This is a very important conclusion, for it means that uncertainties in baseline shifts due to unknown factors are of no engineering consequence.

\section{Discussion and Conclusions}

The records of the large 1999 Chi-Chi, Taiwan earthquake obtained at stations TCU078 and TCU129 have shifts in the acceleration baselines that make it difficult to determine long-period ("static") ground displacements from these records. These baseline shifts, however, have almost no effect on the ground motion at periods less than about $20 \mathrm{~s}$, which are the periods of engineering interest.

Although the origin of the baseline shifts are not certain, very small tilts in the instruments due to differential settlement of the material in the vicinity of the instruments can produce baseline shifts of the order observed in the records, at least for the horizontal components of motion. A tilt of $\theta$ produces a shift in baseline of

$$
\Delta g=g \sin (\Theta)
$$

for horizontal components and

$$
\Delta g=g(1-\cos (\Theta))
$$


for the vertical component. I found that baseline changes of about $1 \mathrm{~cm} / \mathrm{s}^{2}$ occurred on the recordings. From equation (6), this corresponds to a tilt of only 0.001 radians or 0.06 degrees. The change in baseline caused by this very small tilt will produce a large displacement after a long duration - in excess of $10 \mathrm{~m}$ after $50 \mathrm{~s}$. This suggests that even without the type of instrument-dependent baseline shifts discussed by Iwan et al. (1985), it will be very difficult to obtain permanent ground displacements from double integration of horizontal component accelerations. The effect of tilt on vertical components should be much smaller (being proportional to $0.5 \Theta^{2}$ rather than $\Theta$ for small tilts), however, and therefore there is some hope that permanent ground motions can be obtained from vertical recordings. For the records at TCU078 and TCU129, inspection of Figure 3 indicates that the vertical displacements show no sign of leveling off for times long after cessation of strong shaking. This trend, similar to that found for the horizontal components, might be taken as evidence that the vertical recordings are also being affected by unknown baseline shifts. The size of the final displacements, however, requires much larger tilts than needed to explain the horizontal displacements; if the trends are due to baseline shifts, those shifts must be due to something other than tilting. It is possible that the displacements are real. The slip on faults at the Earth's surface often accumulates in a creep-like manner long after the earthquake is over, and therefore displacements obtained from instruments in the vicinity of surface cracks might show ground displacements that do not level off after the strong shaking, in which case the displacements derived from all but the horizontal components at station TCU129 cannot be discounted on the basis of character alone. The horizontal components at station TCU129 can be discounted from their quadratic shape and their large amplitudes.

\section{Acknowledgments}

I thank Willie Lee for prodding me into doing this study, reviewing the manuscript, and providing Figure 1. I also thank Bill Joyner and Chris Stephens for many useful comments. Bill Joyner provided the subroutine for computing a causal Butterworth filter. The routine for computing response spectra is a modified version of "Quake.For", originally written by J.M. Roesset in 1971 and modified by Stavros A. Anagnostopoulos; it uses the method of 
Nigam and Jennings (1969) in which the acceleration is represented by a series of contiguous straight-line segments, and the response is built up from the analytical response of an oscillator to each straight-line segment.

\section{Appendix - Response of an Oscillator to a Step in Acceleration}

The displacement response $u$ of an oscillator due to an impulse in acceleration equal to $a_{b l} \delta(t)$ is

$$
u(t)=-a_{b l} \exp \left(-\omega_{0} \eta t\right) \frac{\sin \omega_{\eta} t}{\omega_{\eta}},
$$

where $\omega_{\eta}=\omega_{0} \sqrt{1-\eta^{2}}$ and $\omega_{0}=2 \pi / T$ is the radial frequency corresponding to the undamped oscillator free-period $T$ and $\eta$ is the fractional damping of the oscillator. From equation (A1), the response to a step in acceleration of height $a_{b l}$ can be obtained by integration, giving

$$
u(t)=-\left(a_{b l} / \omega_{0}^{2}\right)\left\{1-\exp \left(-\omega_{0} \eta t\right)\left[\frac{\eta}{\sqrt{1-\eta^{2}}} \sin \omega_{\eta} t+\cos \omega_{\eta} t\right]\right\}
$$

The response spectrum is given by the maximum of this response. The maximum occurs at the time when the derivative of equation (A2) equals zero. Because the derivative of equation (A2) is equation (A1), the time for a maximum of the response to a step in acceleration is

$$
t_{\max }=\pi / \omega_{\eta}
$$

and the peak response $\left|u_{\max }\right|$ is obtained by substituting equation (A3) into equation (A2), giving

$$
\left|u_{\max }\right|=\left(a_{b l} / \omega_{0}^{2}\right)\left[1+\exp \left(-\eta \pi / \sqrt{1-\eta^{2}}\right)\right]
$$

in terms of radial frequency and

$$
\left|u_{\max }\right|=a_{b l} T^{2} \frac{\left(1+\exp \left(-\eta \pi / \sqrt{1-\eta^{2}}\right)\right)}{4 \pi^{2}}
$$

in terms of period. 


\section{References}

Converse, A. M. (1984). AGRAM: a series of computer programs for processing digitized strong-motion accelerograms, U.S. Geol. Surv. Open-File Rep. 84-525.

Iwan, W. D., M. A. Moser, and C.-Y. Peng (1985). Some observations on strong-motion earthquake measurement using a digital accelerograph, Bull. Seism. Soc. Am. 75, 1225-1246.

Lee, W.H.K. (1999). Report \#3 on the Chi-Chi (Taiwan) earthquake: Examples of nearsource accelerograms in digital files, http://www.iris.washington.edu/taiwan/REPORT3.html.

Nigam, N.C. and P.C. Jennings (1969). Calculation of response spectra from strong-motion earthquake records, Bull. Seism. Soc. Am. 59, 909-922.

Shin, T.C., K.W. Kuo, W.H.K. Lee, T.L. Teng, and Y.B. Tsai (2000). A preliminary report on the 1999 Chi-Chi (Taiwan) earthquake, Seism. Res. Lett. submitted. 


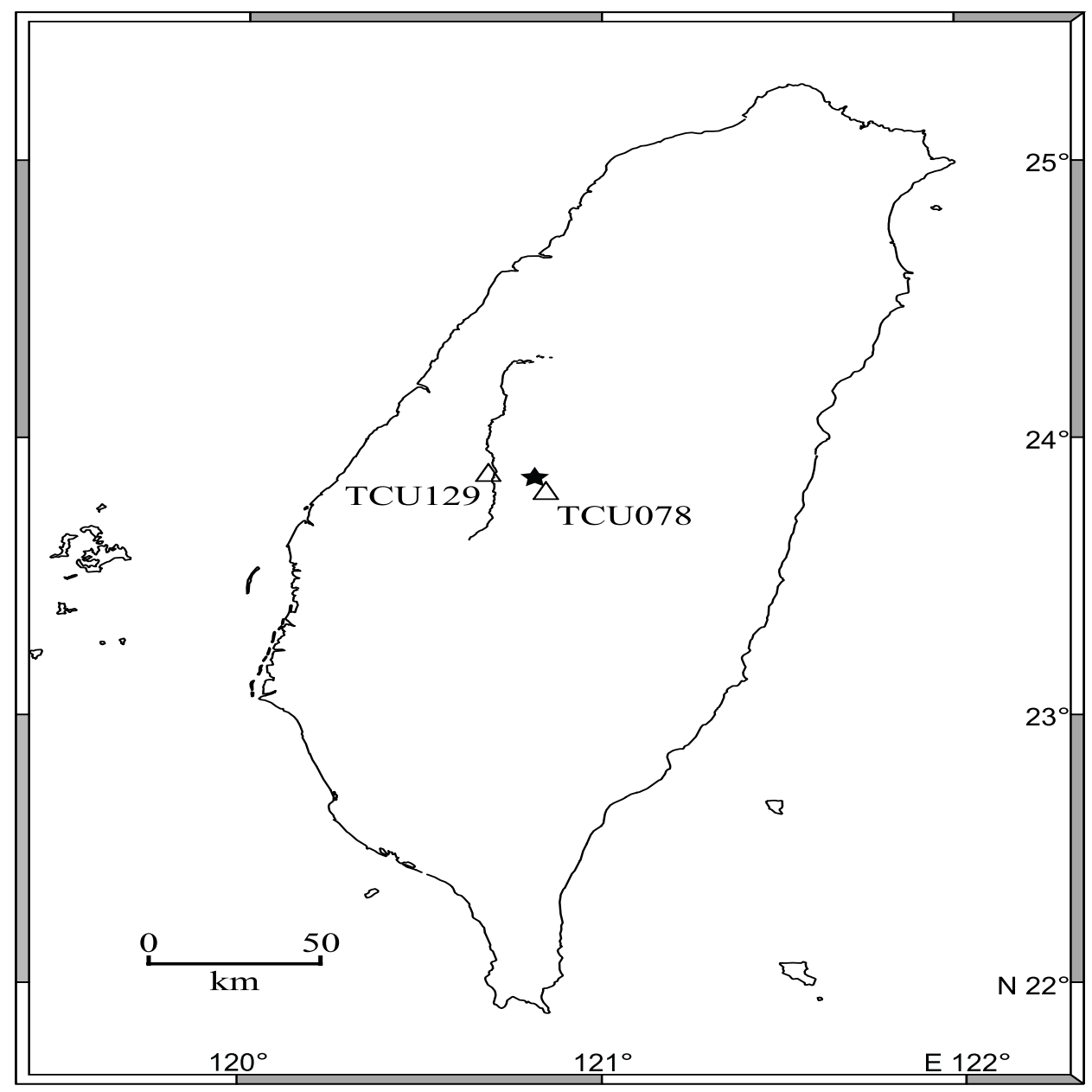

Figure 1. Map showing location of stations TCU078 and TCU129, along with epicenter (star) and mapped surface faulting. 


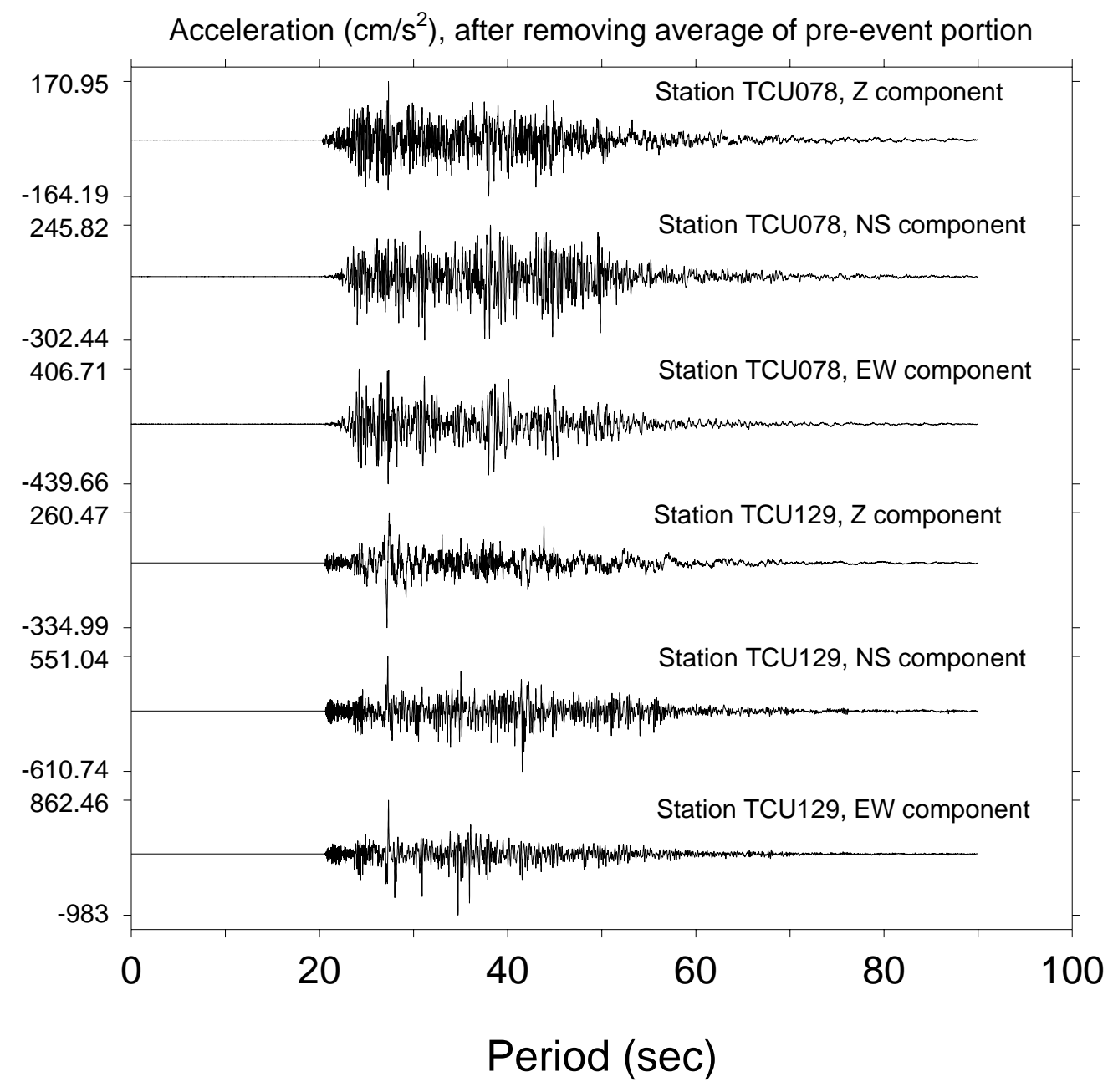

Jan 14, 2000 9:14:57 am C:IPSVTAIWAN99ITS_ALL_A.GRA C:IPSVTAIWAN99ITS_ALL_A.DT

Figure 2. Acceleration time series analyzed in this report, after removing the pre-event average from the whole record. Note that each time series has been plotted using independent scales; the peak excursions are indicated on the left. 


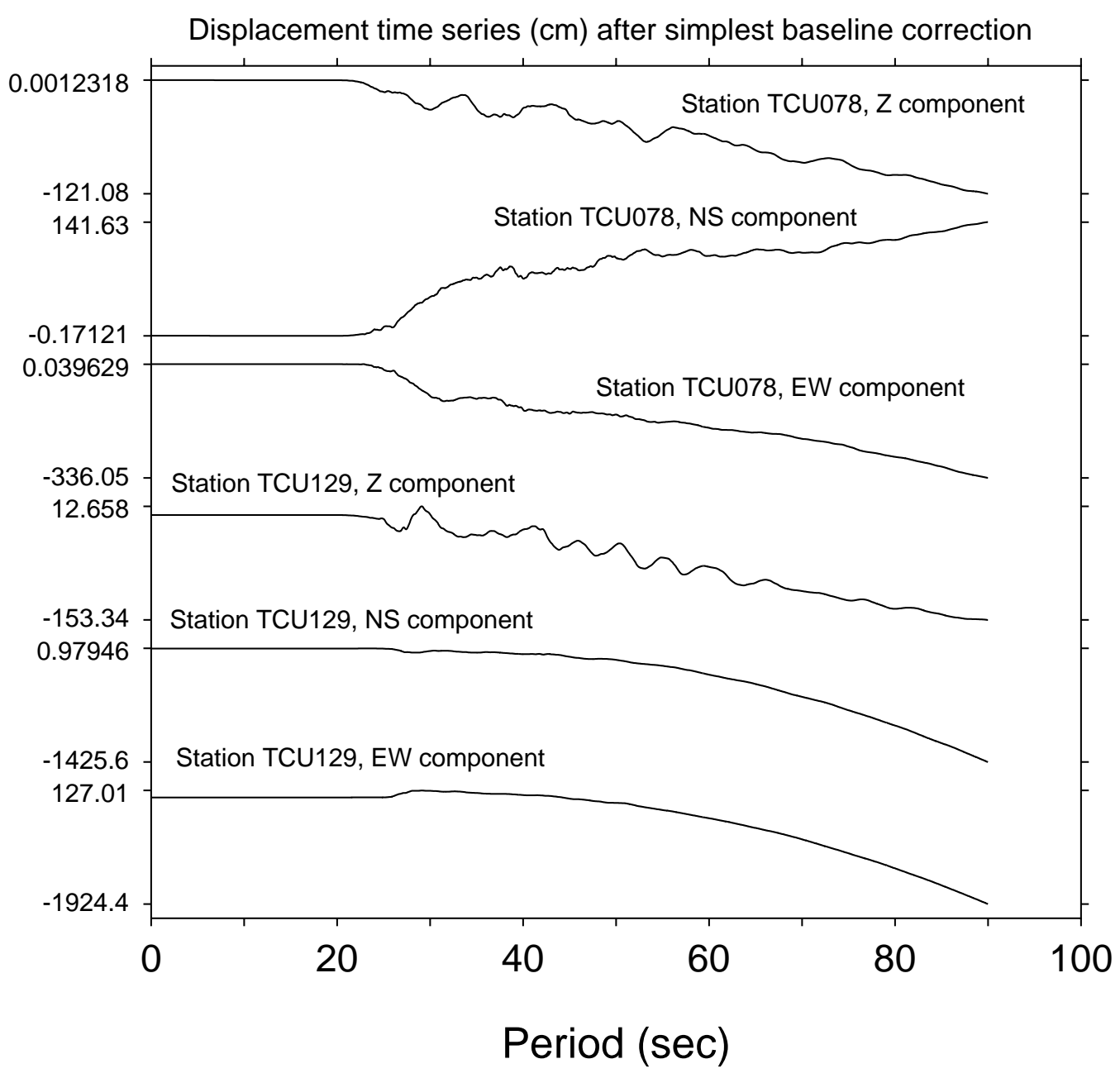

Oct 27, 1999 11:22:10 am C:IPSVITAIWAN99ITS_DIS.GRA C:IPSVTAIWAN99ITS_DIS.DT

Figure 3. Displacement time series resulting from doubly integrating the acceleration traces after removal of the baseline given by the average of the pre-event portion of the record. Note that each time series has been plotted using independent scales; the peak excursions are indicated on the left. 


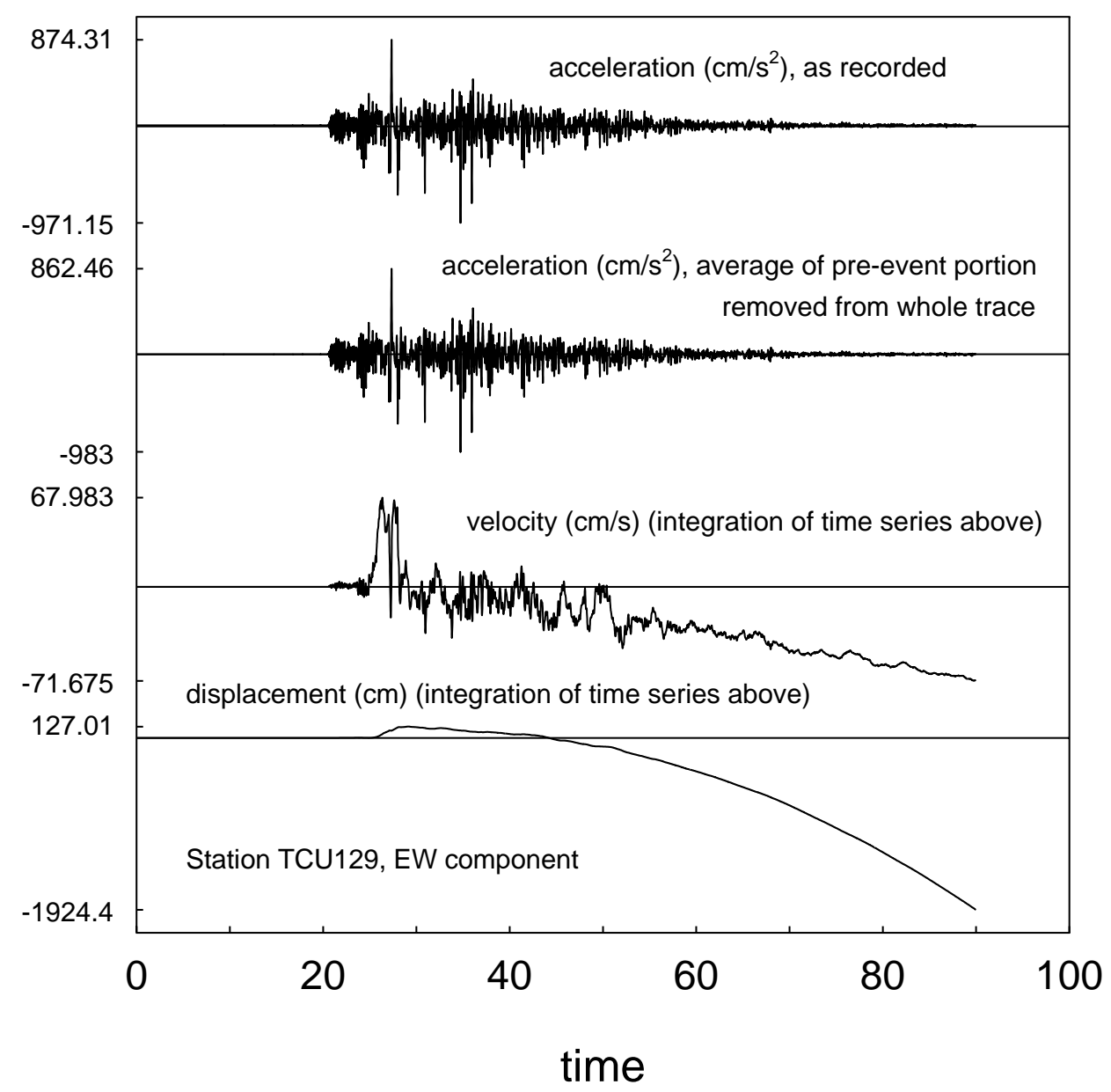

Oct 27, 1999 11:22:10 am

C:IPSVTTAIWAN99ITS129AVD.GRA

C:IPSVTAIWAN99ITS129AVD.DT

Figure 4. Processing of the acceleration recorded at station TCU129 in the E-W direction. For reference, a zero line is shown in each plot. From the top: 1) as recorded (barely visible is the small offset of about $\left.12 \mathrm{~cm} / \mathrm{s}^{2}\right) ; 2$ ) the acceleration after removing the baseline determined from the average of the pre-event portion $\left.\left(11.85 \mathrm{~cm} / \mathrm{s}^{2}\right) ; 3\right)$ integration of the baseline-corrected acceleration to yield velocity; 4) integration of the velocity to obtain ground displacement. 


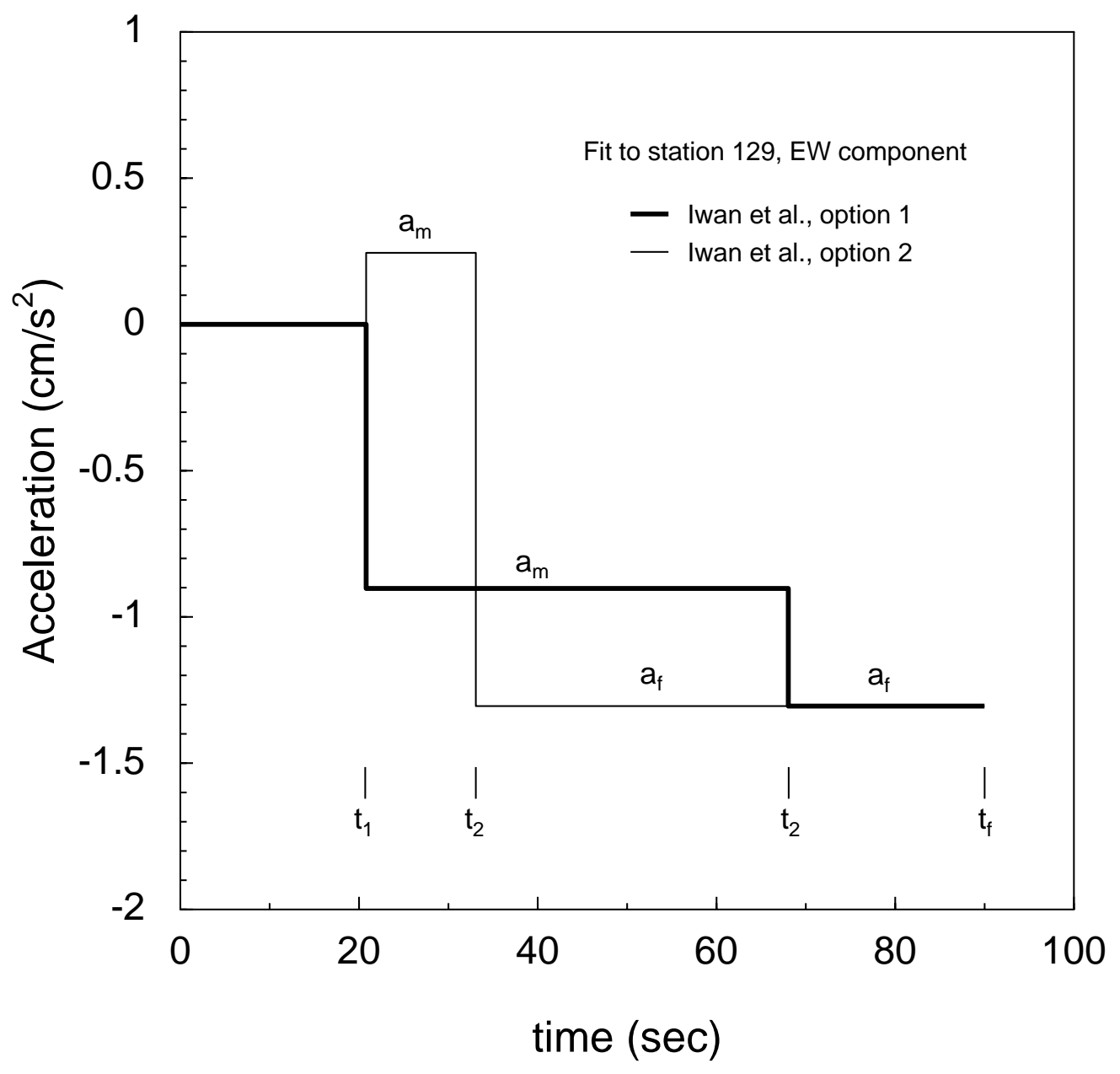

Oct 20, 1999 8:18:14 am C:IPSVTAIWAN99IT129_A.GRA

C:IPSVTAIWAN99IAVD.DT

Figure 5. The baseline corrections for Iwan et al.'s (1985) options 1 and 2. 


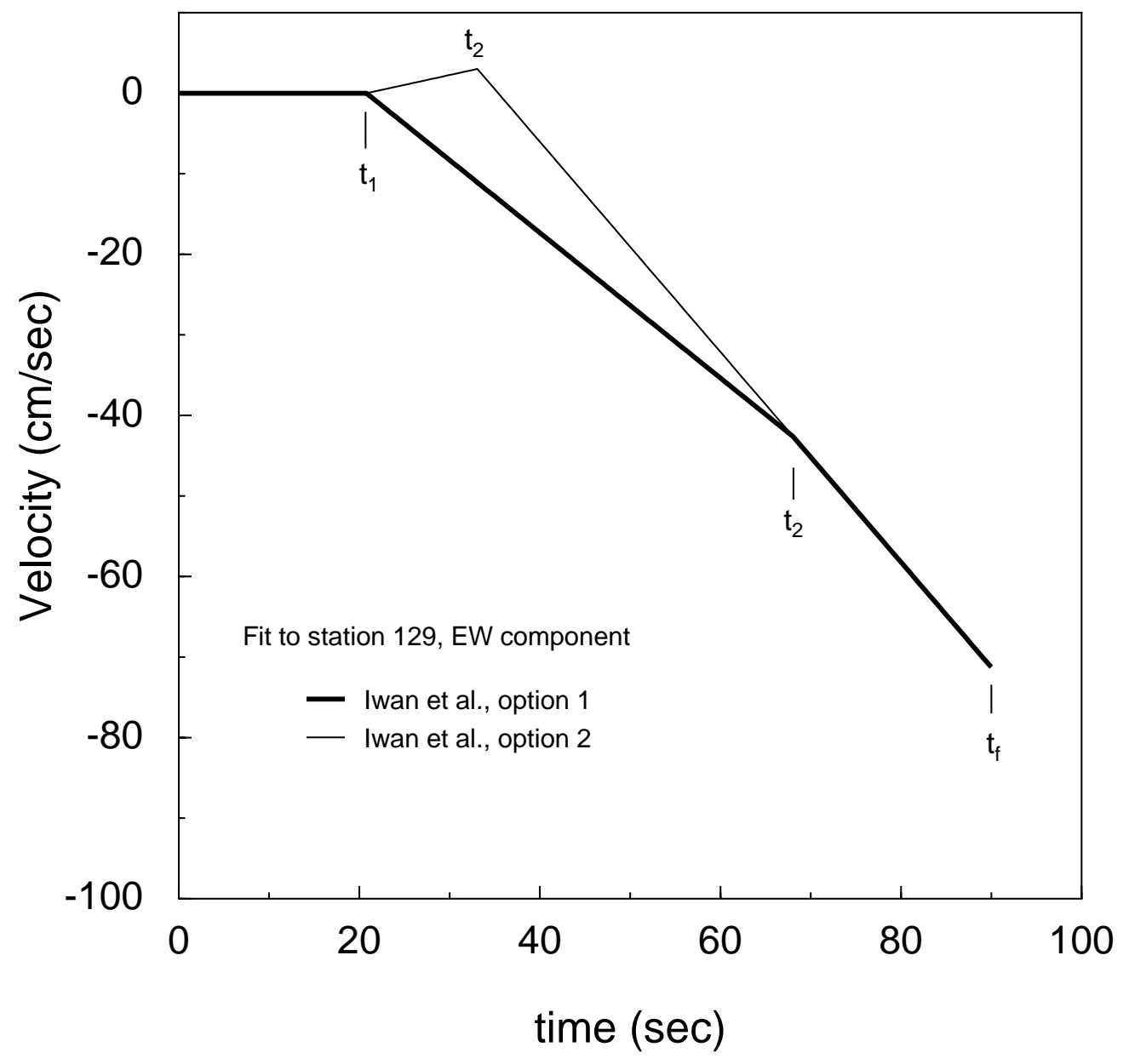

Oct 20, 1999 7:57:08 am C:IPSVITAIWAN99IT129_V.GRA C:IPSVTAIWAN99IAVD.DT

Figure 6. The velocity function from which Iwan et al.'s (1985) baseline correction is determined. 


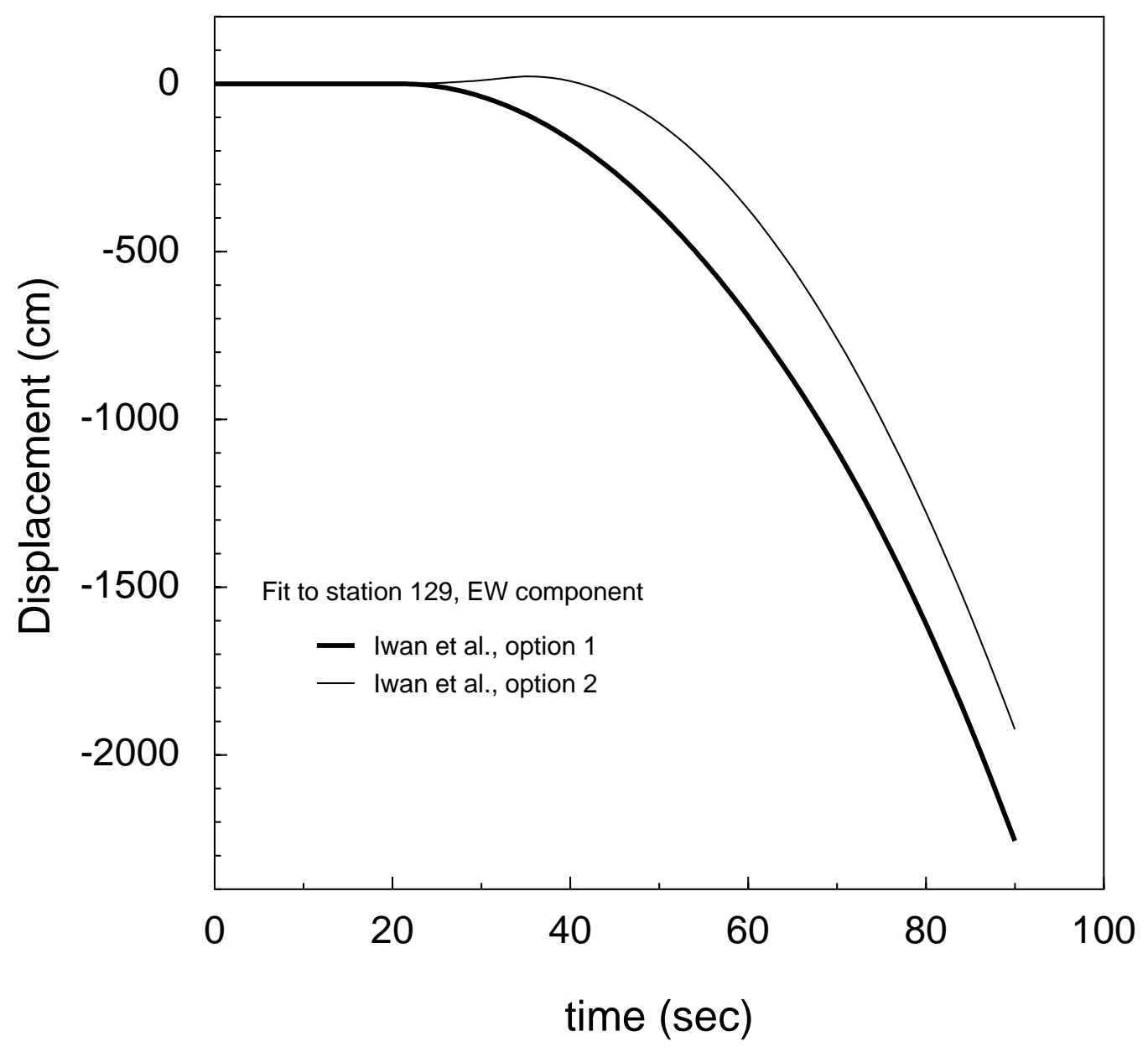

Oct 17, 1999 4:34:40 pm

C:IPSVTAIWAN99IT129_D.GRA

C:IPSVTAIWAN99IAVD.DT

Figure 7. The doubly integrated acceleration baseline correction for Iwan et al.'s (1985) options 1 and 2 . 


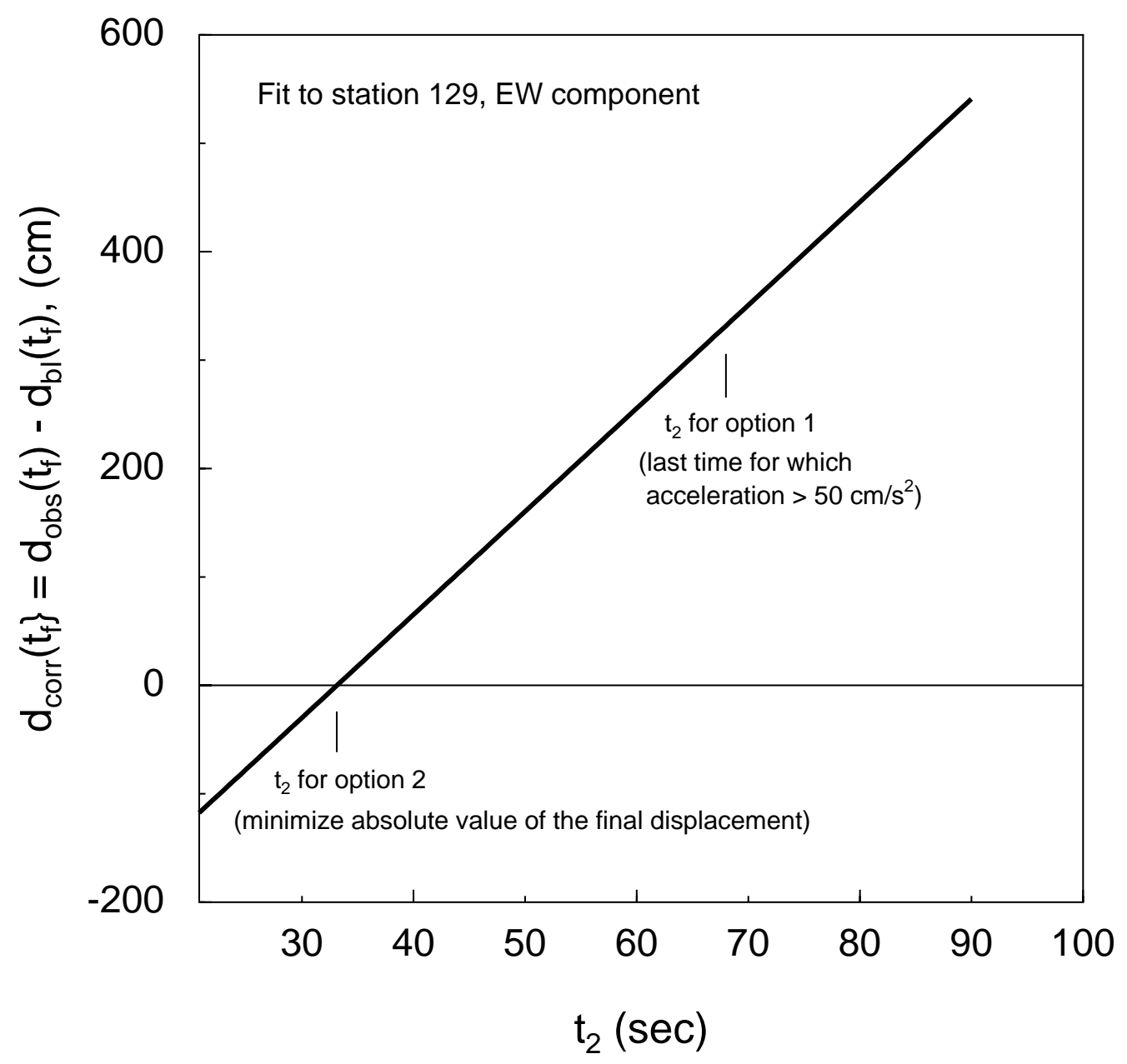

Oct 20, 1999 8:19:30 am

C:IPSVTTAIWAN99IT129 MIN.GRA

C:IPSVTAIWAN99IAVD.DT

Figure 8. The dependence of the final displacement on the choice of the time $t_{2}$. Indicated are the values of $t_{2}$ corresponding to Iwan et al.'s (1985) options 1 and 2 . 


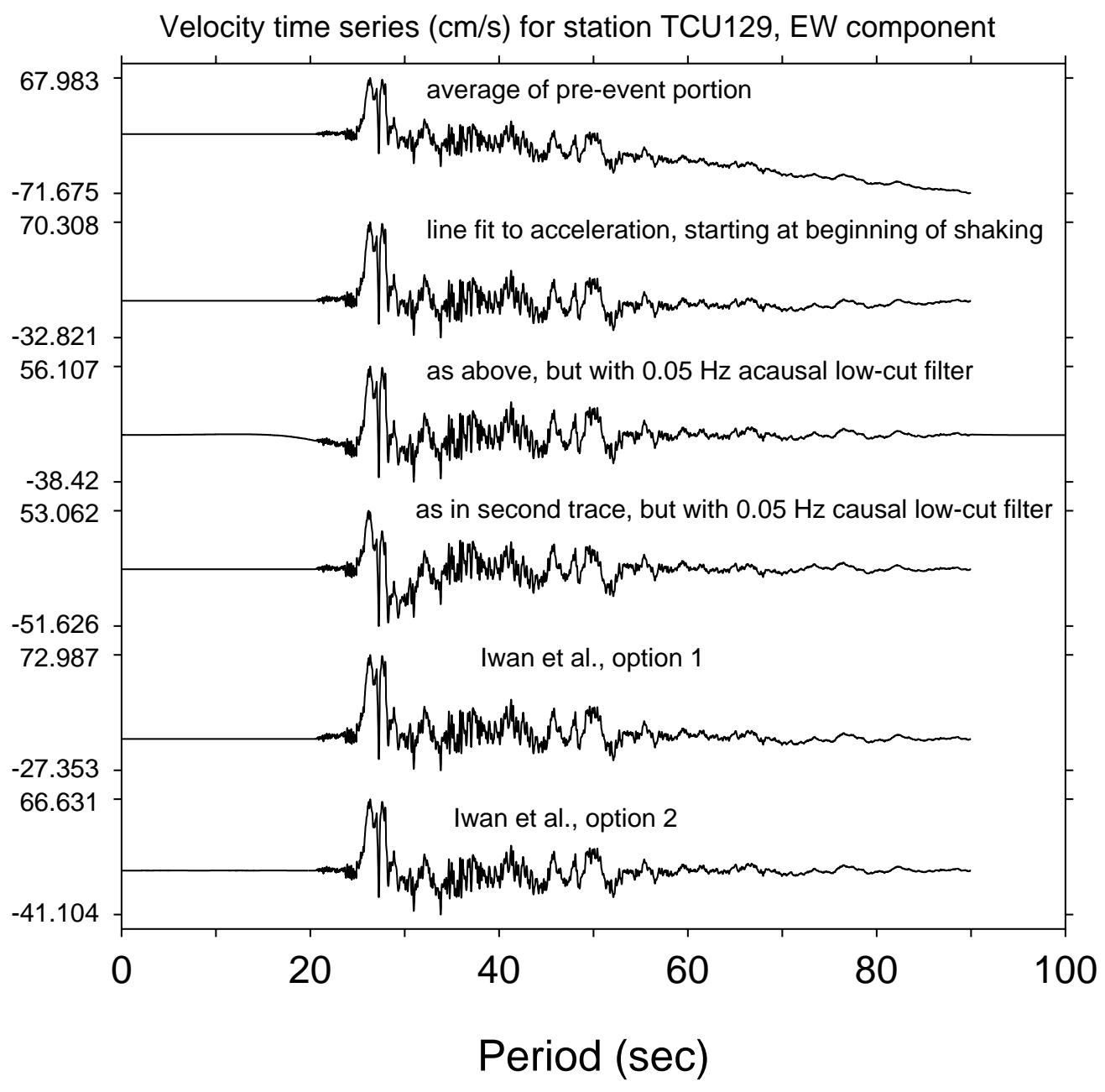

Oct 27, 1999 11:22:10 am

C:IPSVITAIWAN99ITS1293_V.GRA

C:IPSVITAIWAN99ITS1293_V.DT

Figure 9. Comparison of velocity time series derived from the EW component of ground acceleration recorded at station TCU129 after different baseline corrections were applied to the recorded acceleration. 


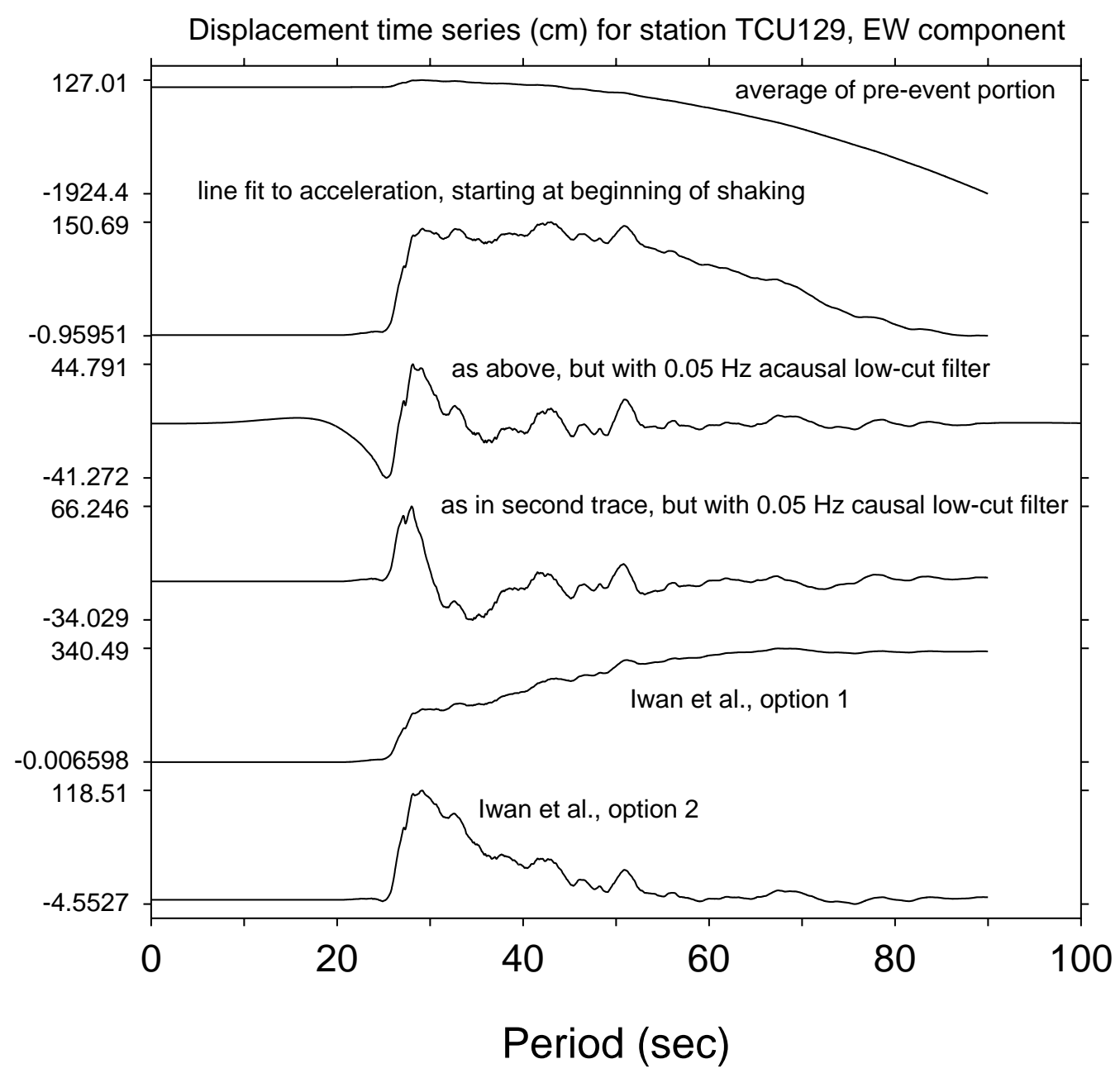

Oct 27, 1999 11:22:10 am

C:IPSVITAIWAN99ITS1293D2.GRA

C:IPSVTAIWAN99ITS1293_D.DT

Figure 10. Comparison of displacement time series derived from the EW component of ground acceleration recorded at station TCU129 after different baseline corrections were applied to the recorded acceleration, displayed using individual scaling. 


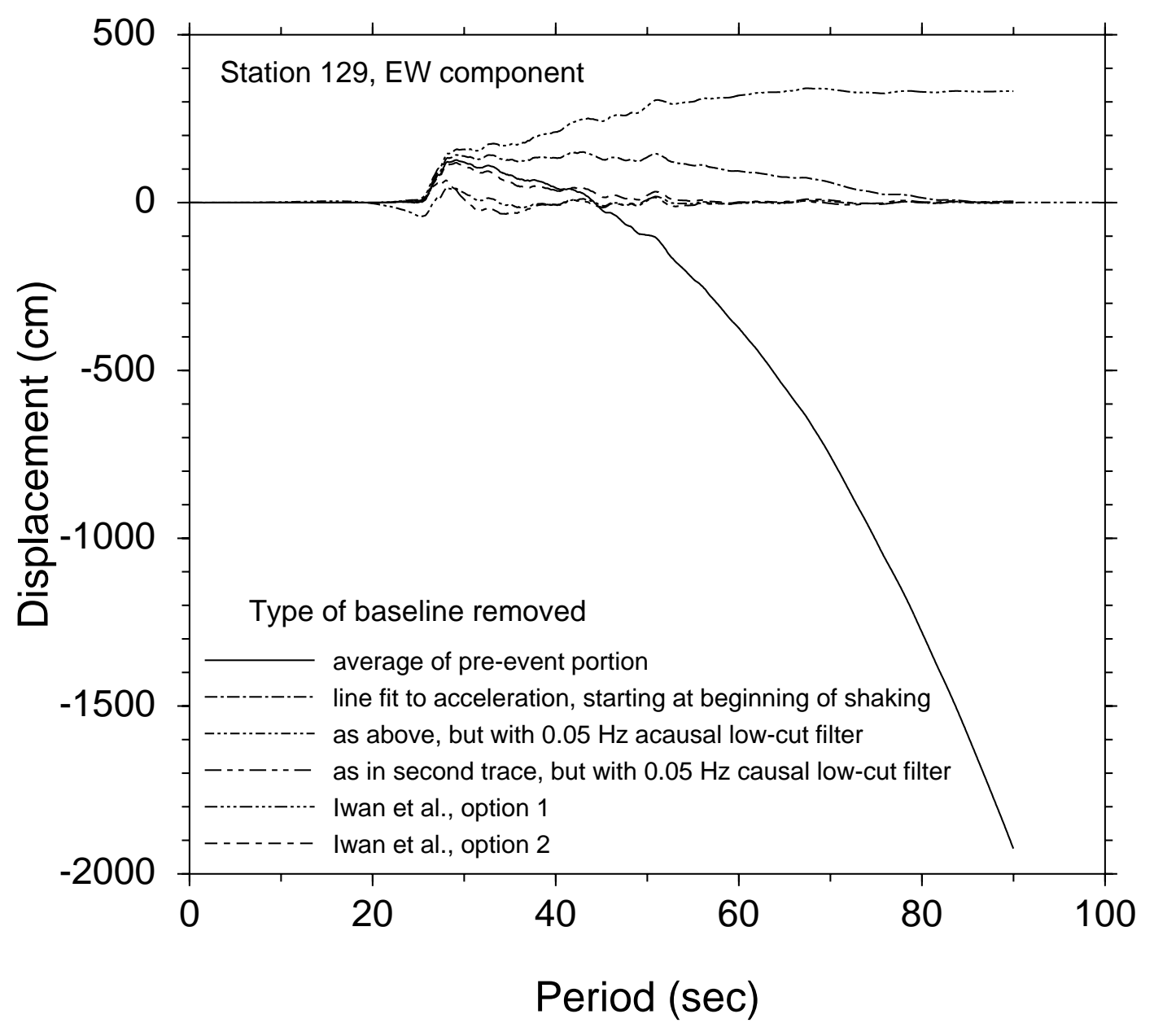

Oct 18, 1999 6:39:06 pm

C:IPSVITAIWAN99ITS1293_D.GRA

C:IPSVTAIWAN99ITS1293_D.DT

Figure 11. Comparison of displacement time series derived from the EW component of ground acceleration recorded at station TCU129 after different baseline corrections were applied to the recorded acceleration, overlain to emphasize similarities and differences. 


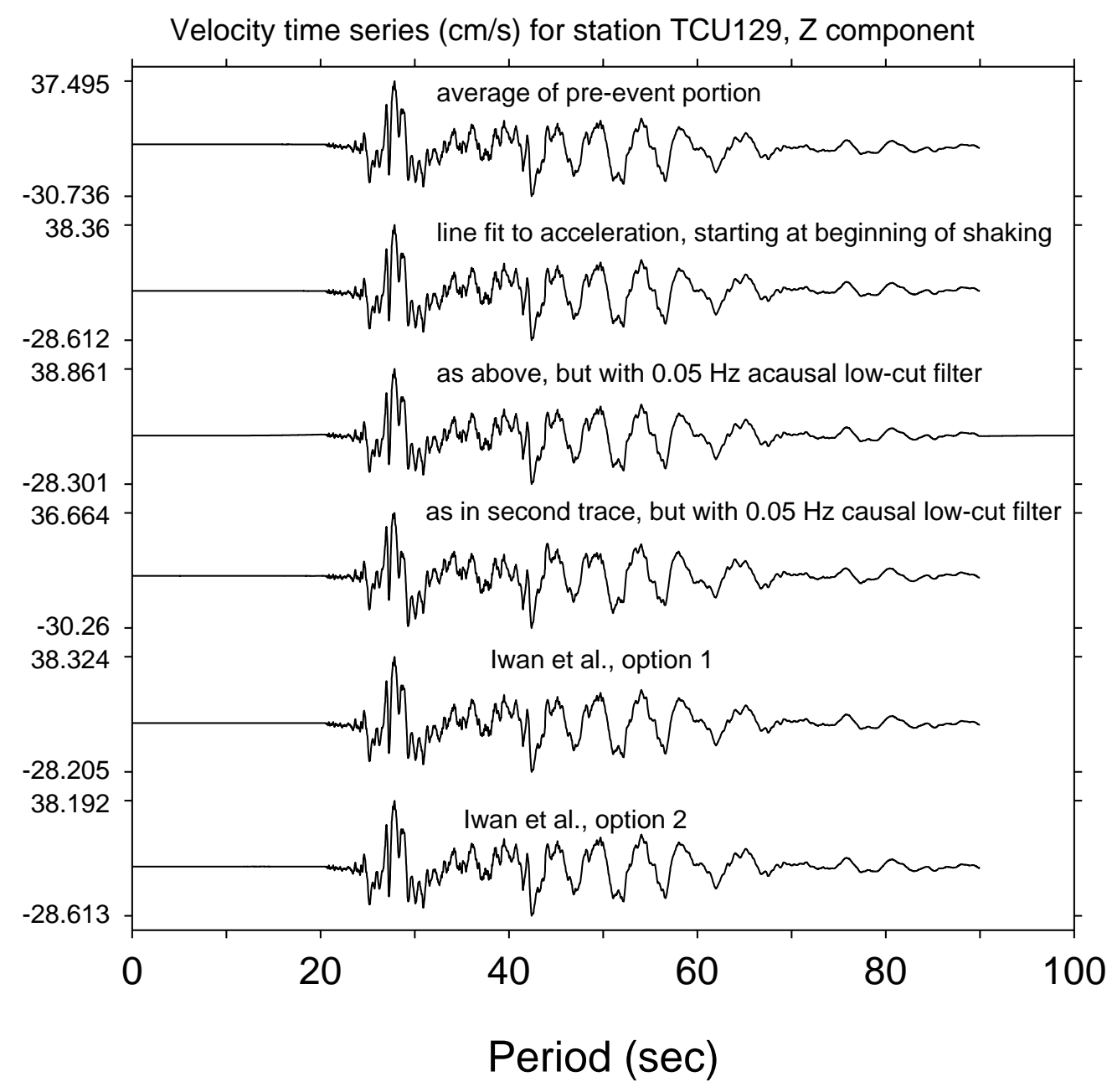

Oct 27, 1999 11:22:10 am

C:IPSVITAIWAN99ITS1291_V.GRA

C:IPSVTAIWAN99ITS1291_V.DT

Figure 12. Comparison of velocity time series derived from the $\mathrm{Z}$ component of ground acceleration recorded at station TCU129 after different baseline corrections were applied to the recorded acceleration. 


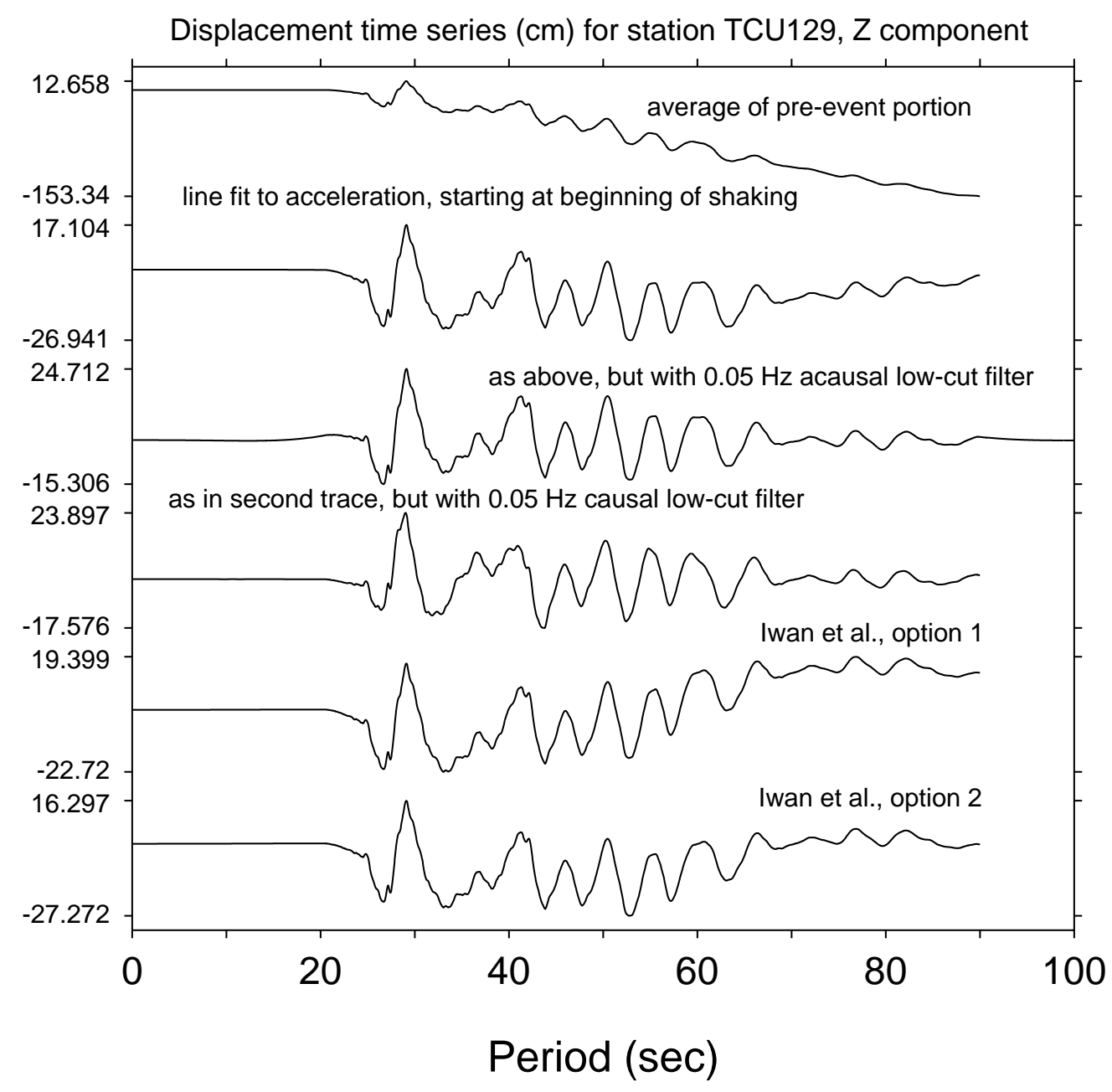

Oct 27, 1999 11:22:10 am

C:IPSVITAIWAN99ITS1291D2.GRA

C:IPSVTAIWAN99ITS1291_D.DT

Figure 13. Comparison of displacement time series derived from the $\mathrm{Z}$ component of ground acceleration recorded at station TCU129 after different baseline corrections were applied to the recorded acceleration. 


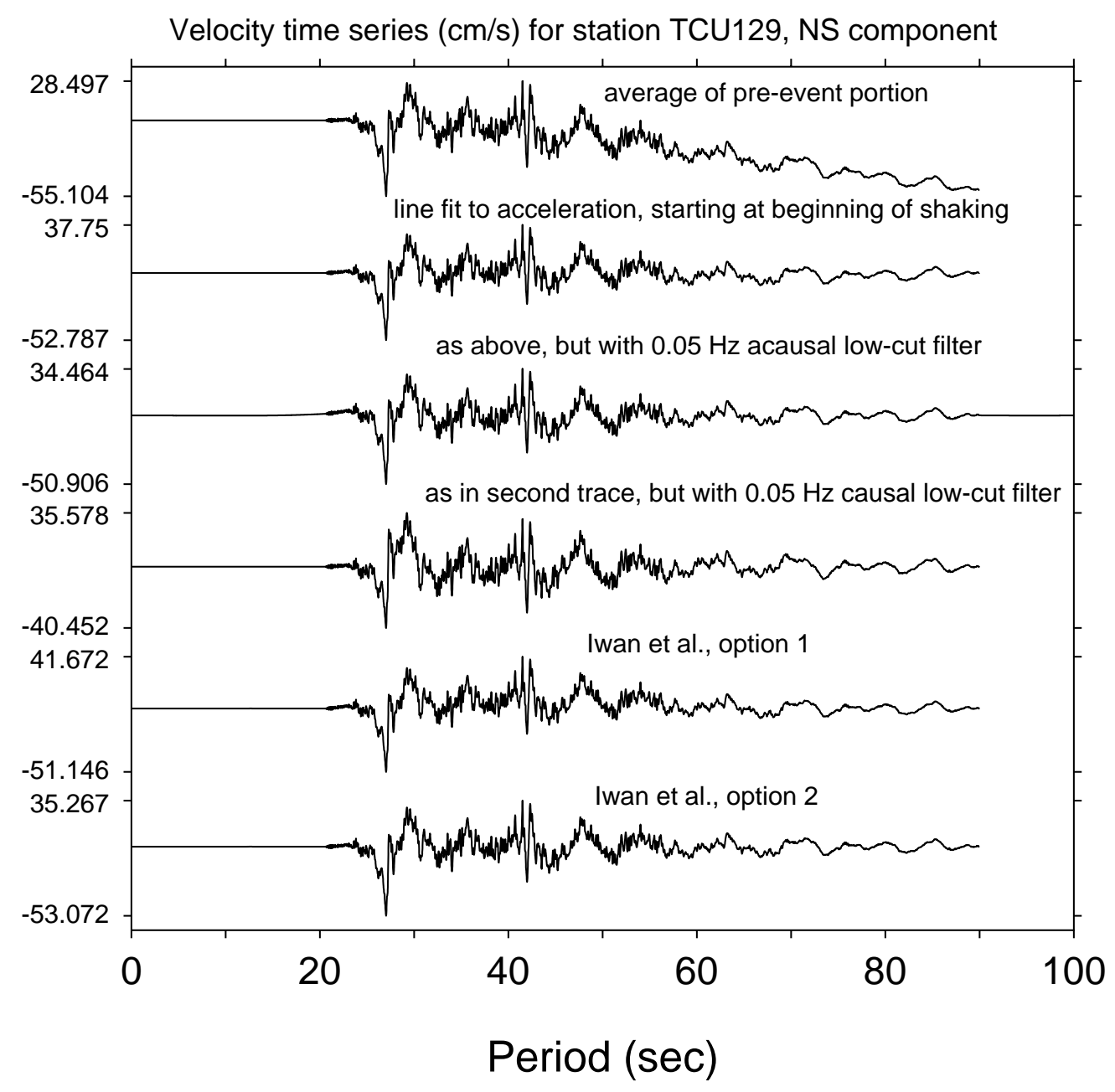

Oct 27, 1999 11:22:10 am

C:IPSVTAIWAN99ITS1292_V.GRA

C:IPSVITAIWAN99ITS1292_V.DT

Figure 14. Comparison of velocity time series derived from the NS component of ground acceleration recorded at station TCU129 after different baseline corrections were applied to the recorded acceleration. 


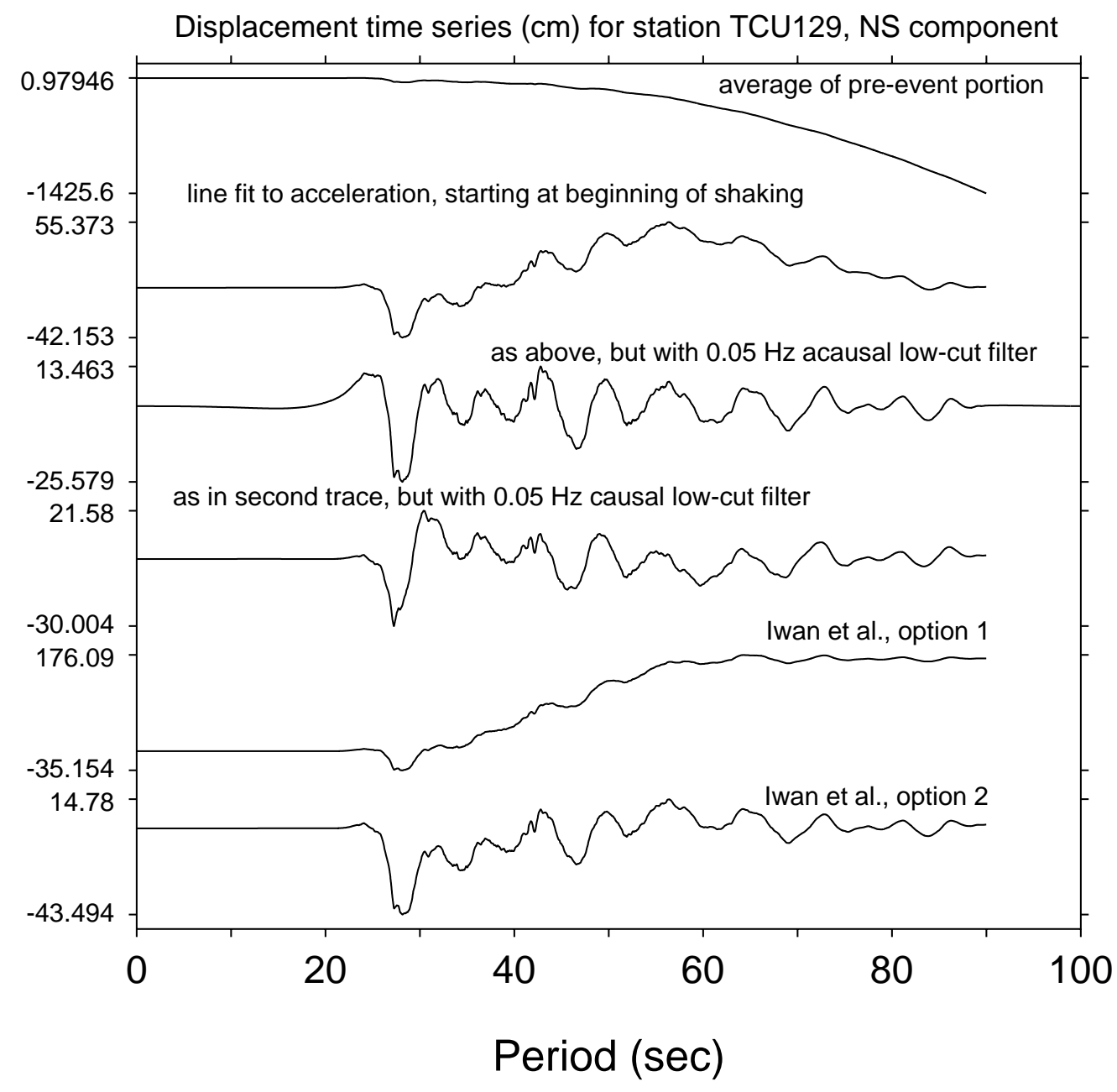

Oct 27, 1999 11:22:10 am

C:IPSVITAIWAN99ITS1292D2.GRA

C:IPSVITAIWAN99ITS1292_D.DT

Figure 15. Comparison of displacement time series derived from the NS component of ground acceleration recorded at station TCU129 after different baseline corrections were applied to the recorded acceleration. 


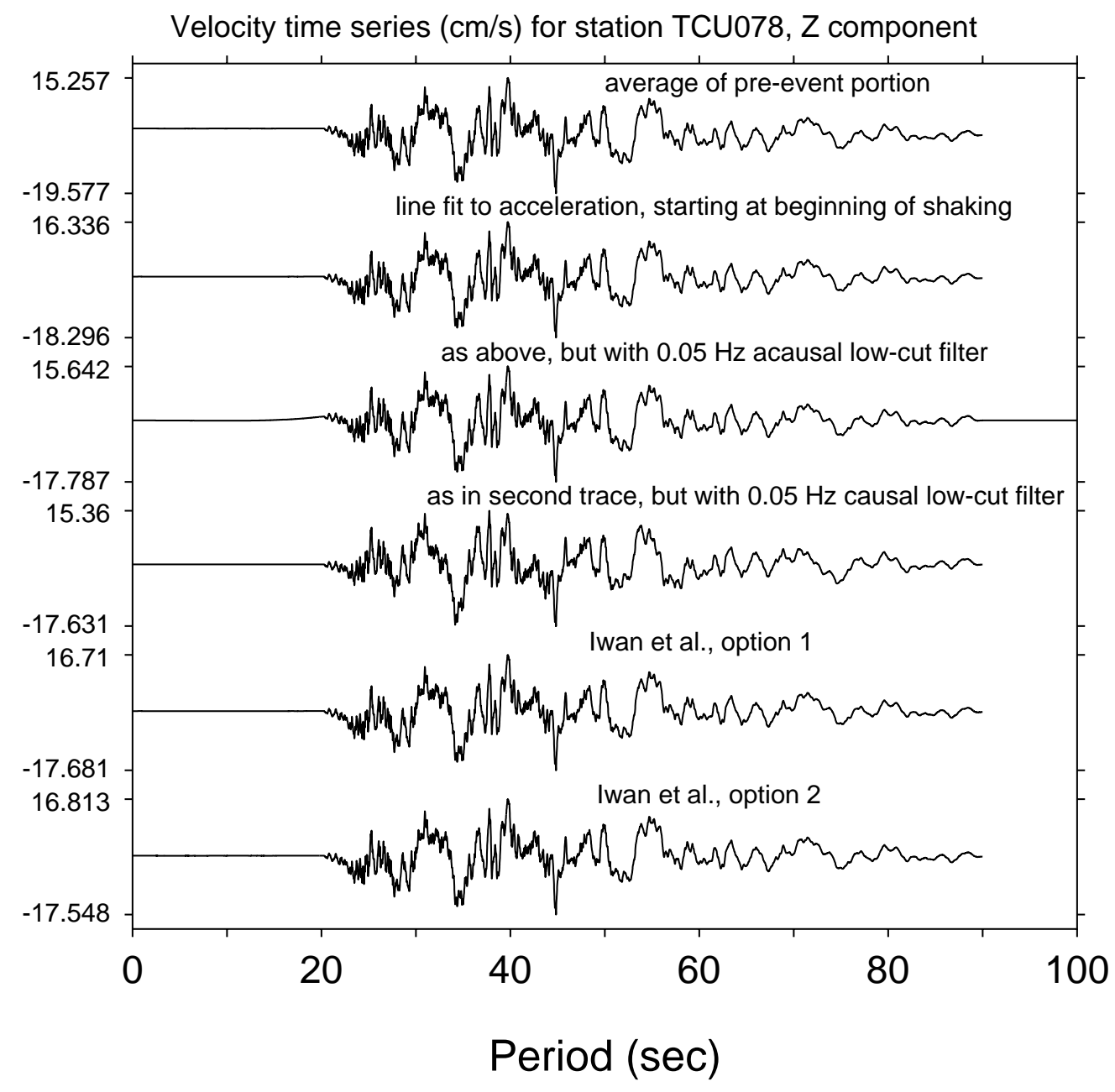

Oct 27, 1999 11:22:10 am

C:IPSVITAIWAN99ITS0781_V.GRA

C:IPSVTAIWAN99ITS0781_V.DT

Figure 16. Comparison of velocity time series derived from the $\mathrm{Z}$ component of ground acceleration recorded at station TCU078 after different baseline corrections were applied to the recorded acceleration. 


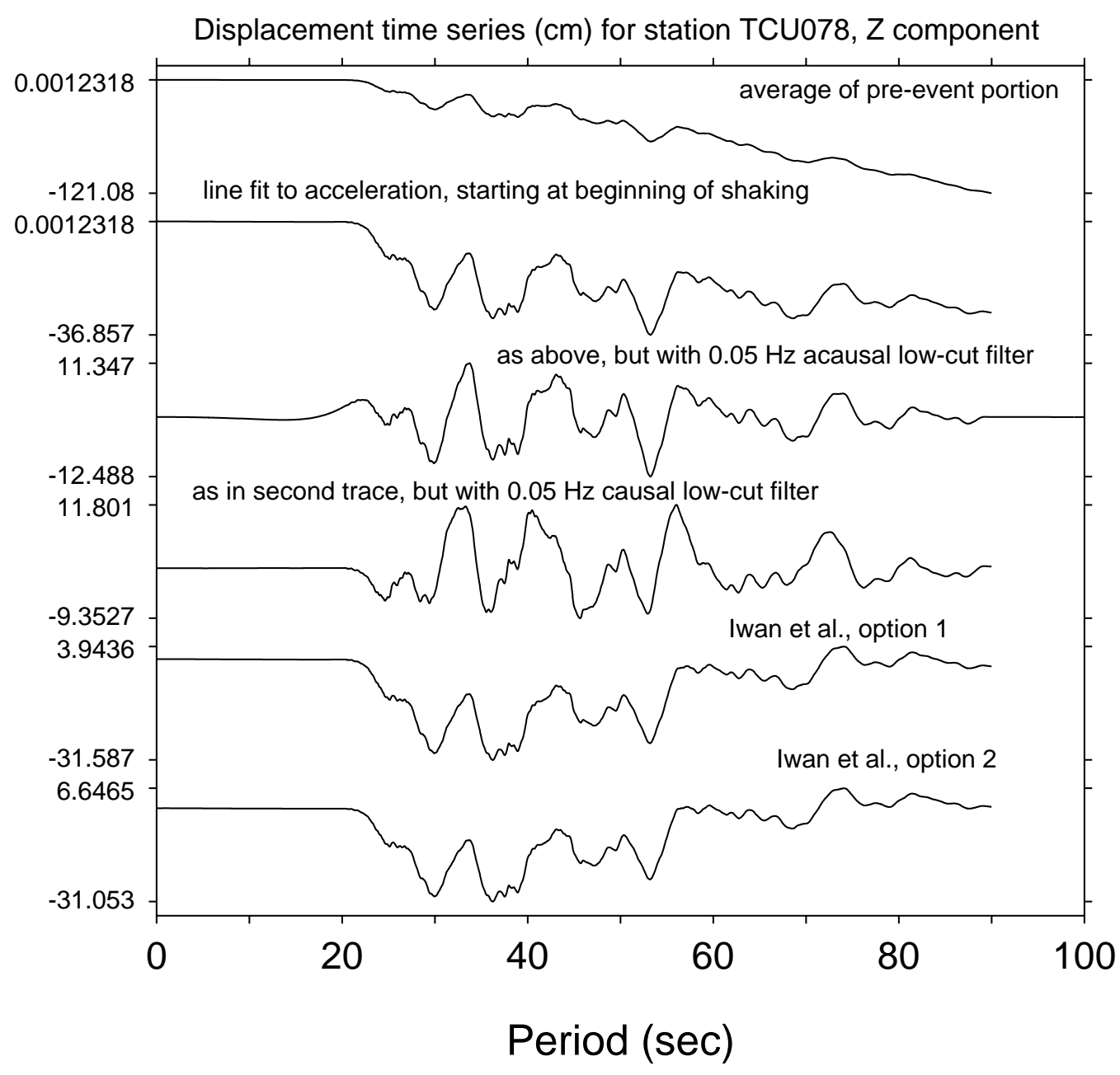

Oct 27, 1999 11:22:10 am

C:IPSVITAIWAN99ITS0781D2.GRA

C:IPSVTTAIWAN99ITS0781_D.DT

Figure 17. Comparison of displacement time series derived from the Z component of ground acceleration recorded at station TCU078 after different baseline corrections were applied to the recorded acceleration. 


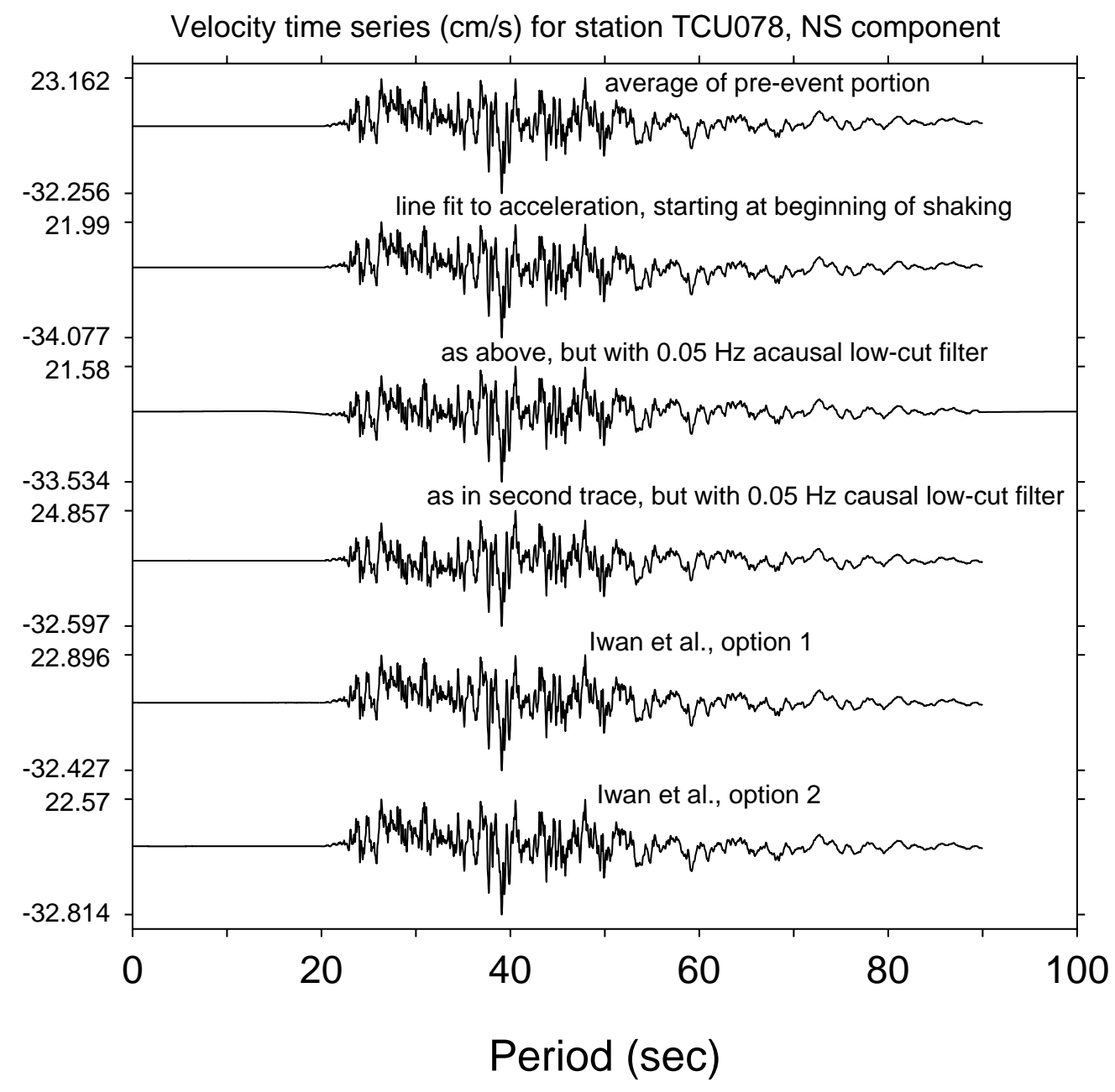

Oct 27, 1999 11:22:10 am

C:IPSVITAIWAN99ITS0782_V.GRA

C:IPSVTAIWAN99ITS0782_V.DT

Figure 18. Comparison of velocity time series derived from the NS component of ground acceleration recorded at station TCU078 after different baseline corrections were applied to the recorded acceleration. 


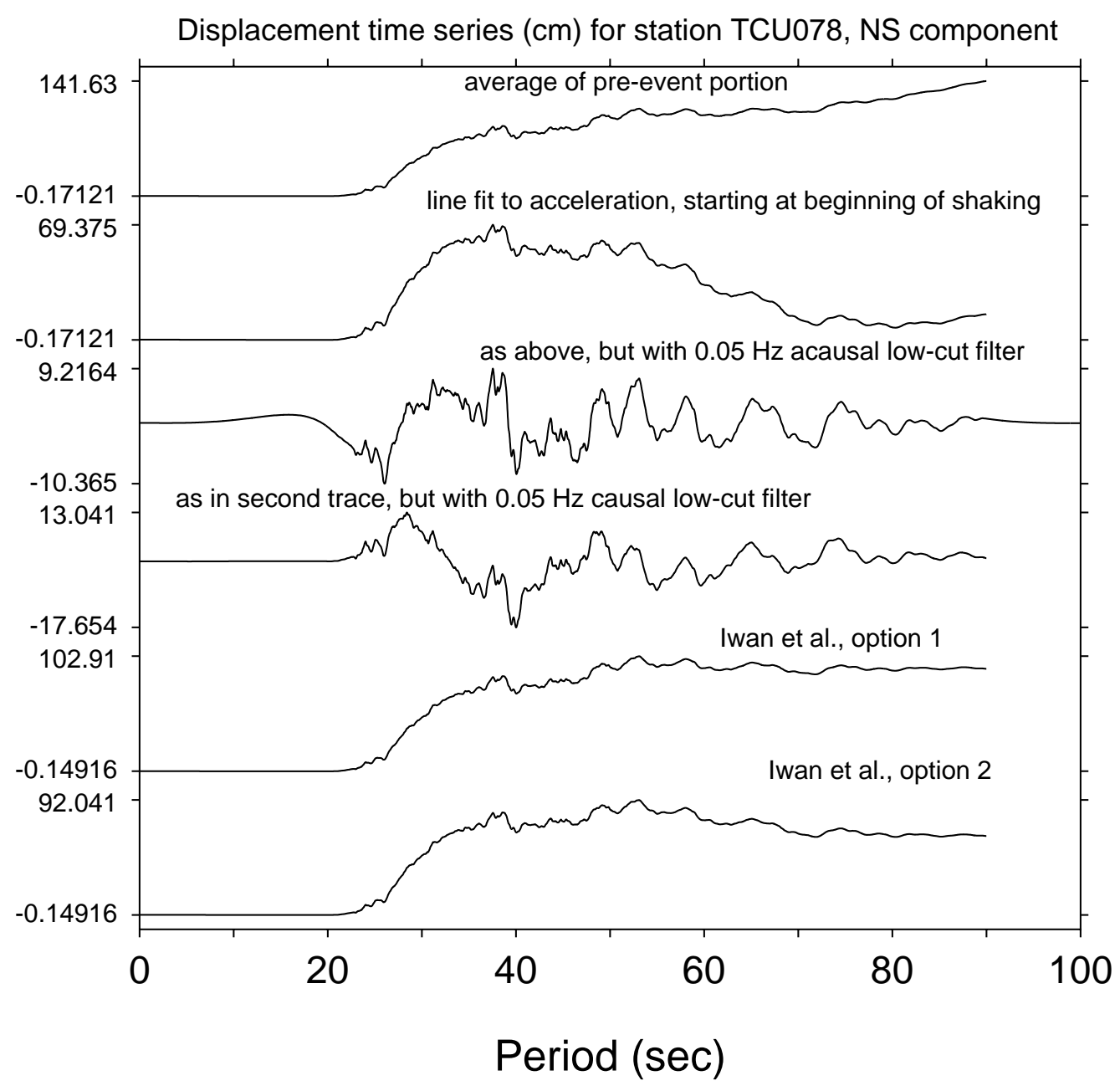

Oct 27, 1999 11:22:10 am

C:IPSVITAIWAN99ITS0782D2.GRA

C:IPSVITAIWAN991TS0782_D.DT

Figure 19. Comparison of displacement time series derived from the NS component of ground acceleration recorded at station TCU078 after different baseline corrections were applied to the recorded acceleration. 


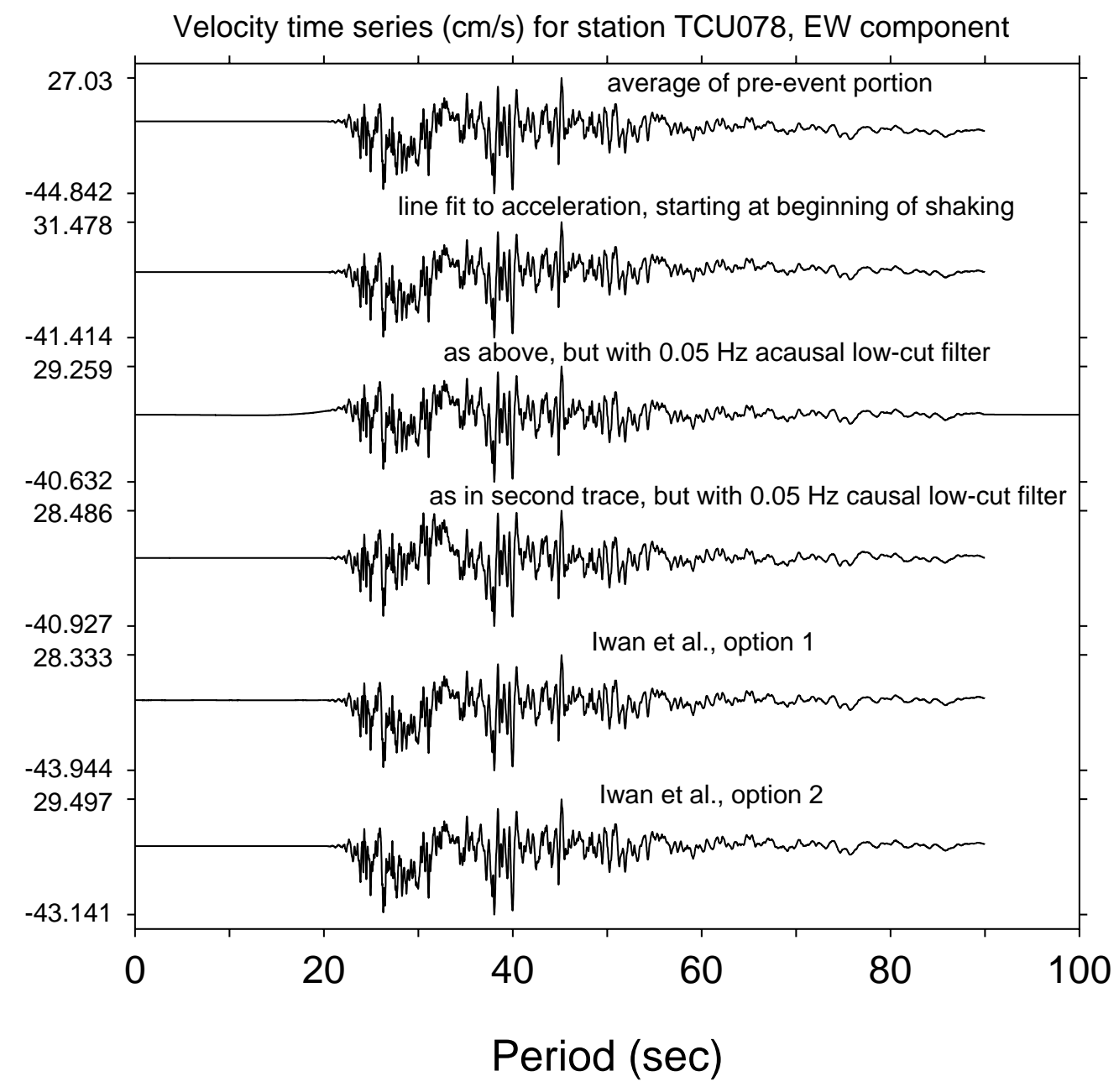

Oct 27, 1999 11:22:10 am

C:IPSVITAIWAN99ITS0783_V.GRA

C:IPSVTAIWAN99ITS0783_V.DT

Figure 20. Comparison of velocity time series derived from the EW component of ground acceleration recorded at station TCU078 after different baseline corrections were applied to the recorded acceleration. 


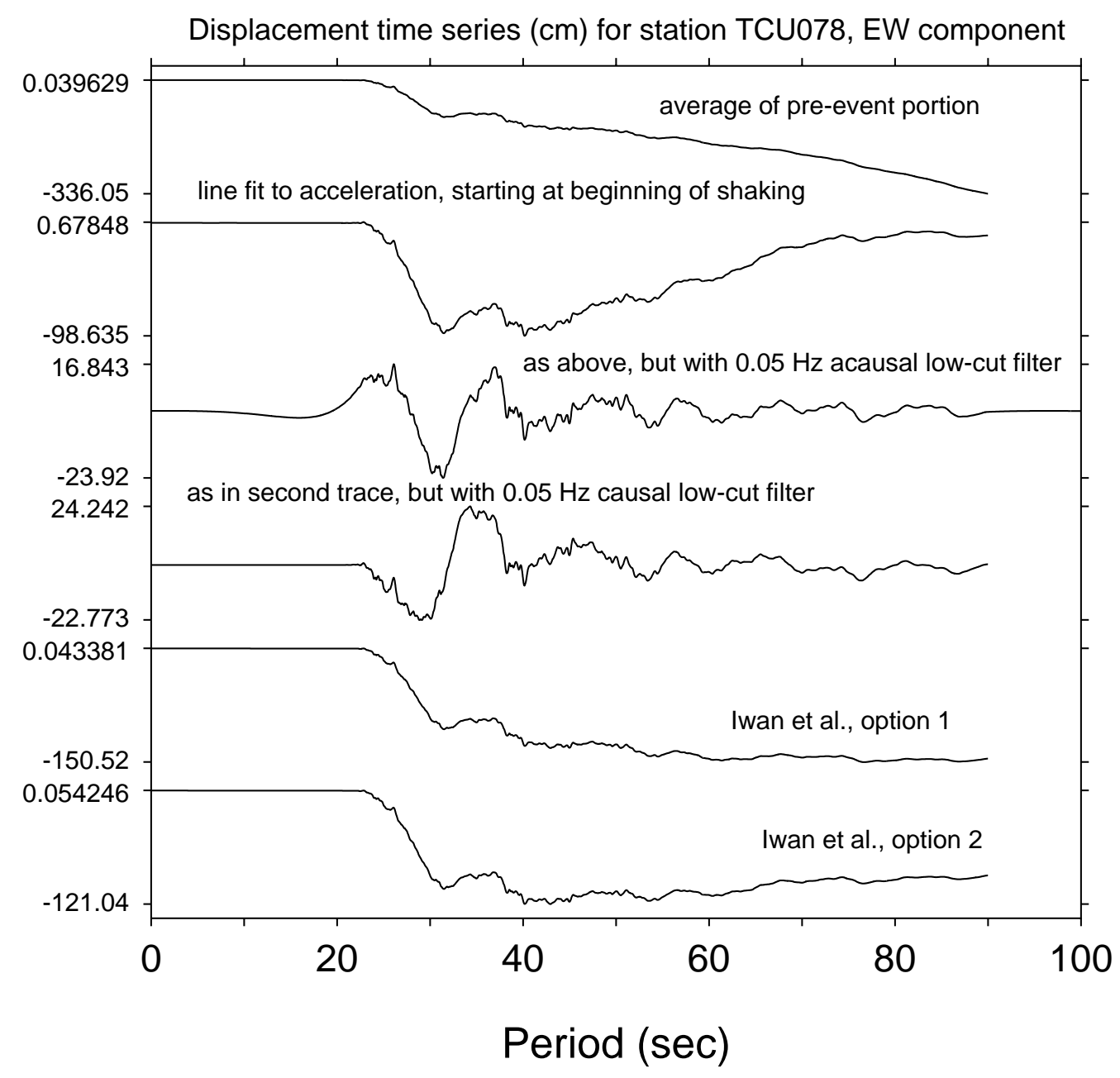

Oct 27, 1999 11:22:10 am

C:IPSVITAIWAN99ITS0783D2.GRA

C:IPSVITAIWAN99ITS0783_D.DT

Figure 21. Comparison of displacement time series derived from the EW component of ground acceleration recorded at station TCU078 after different baseline corrections were applied to the recorded acceleration. 


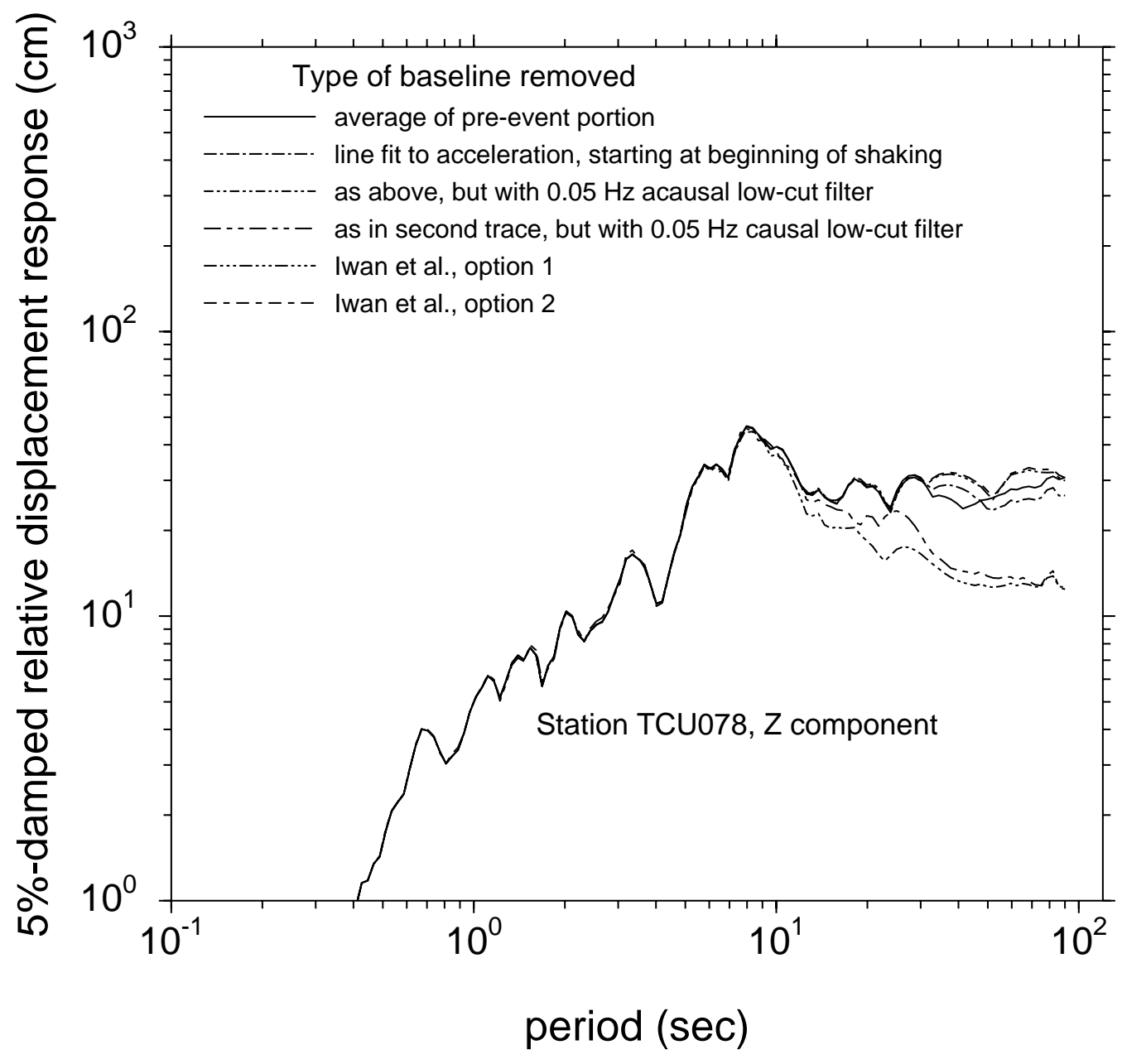

Dec 6, 1999 10:46:46 am D:IPSVITAIWAN99IT0781_RS.GRA D:IPSVTAIWAN99IT0781_RS.DT

Figure 22. 5\% -damped response spectra for the accelerations recorded at station TCU078 in the $\mathrm{Z}$ direction, corrected using the baseline-correction schemes considered in this report. 


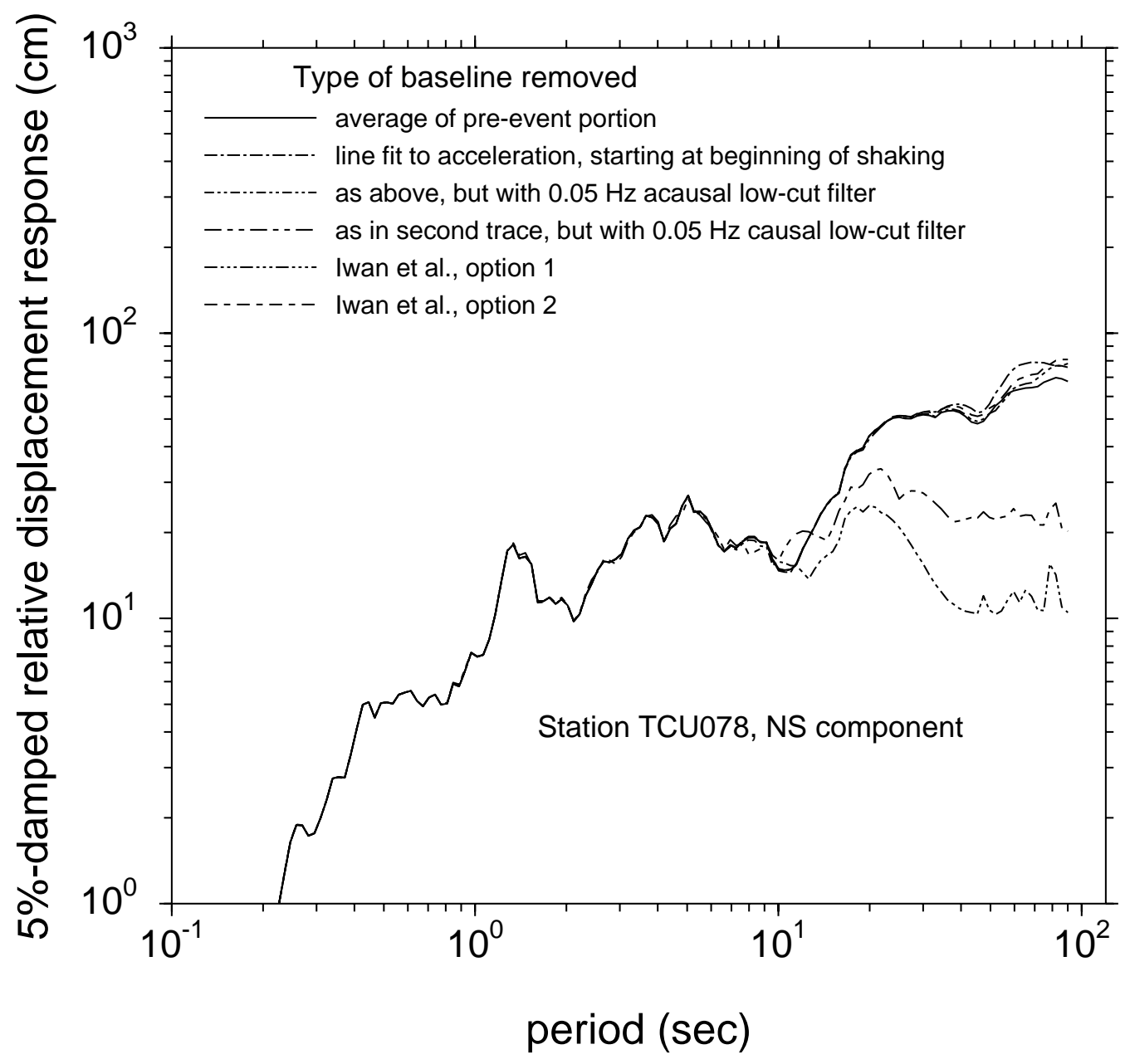

Dec 6, 1999 10:49:12 am

D:IPSVTAIWAN99IT0782_RS.GRA

D:IPSVTAIWAN99IT0782_RS.DT

Figure 23. 5\% - damped response spectra for the accelerations recorded at station TCU078 in the N-S direction, corrected using the baseline-correction schemes considered in this report. 


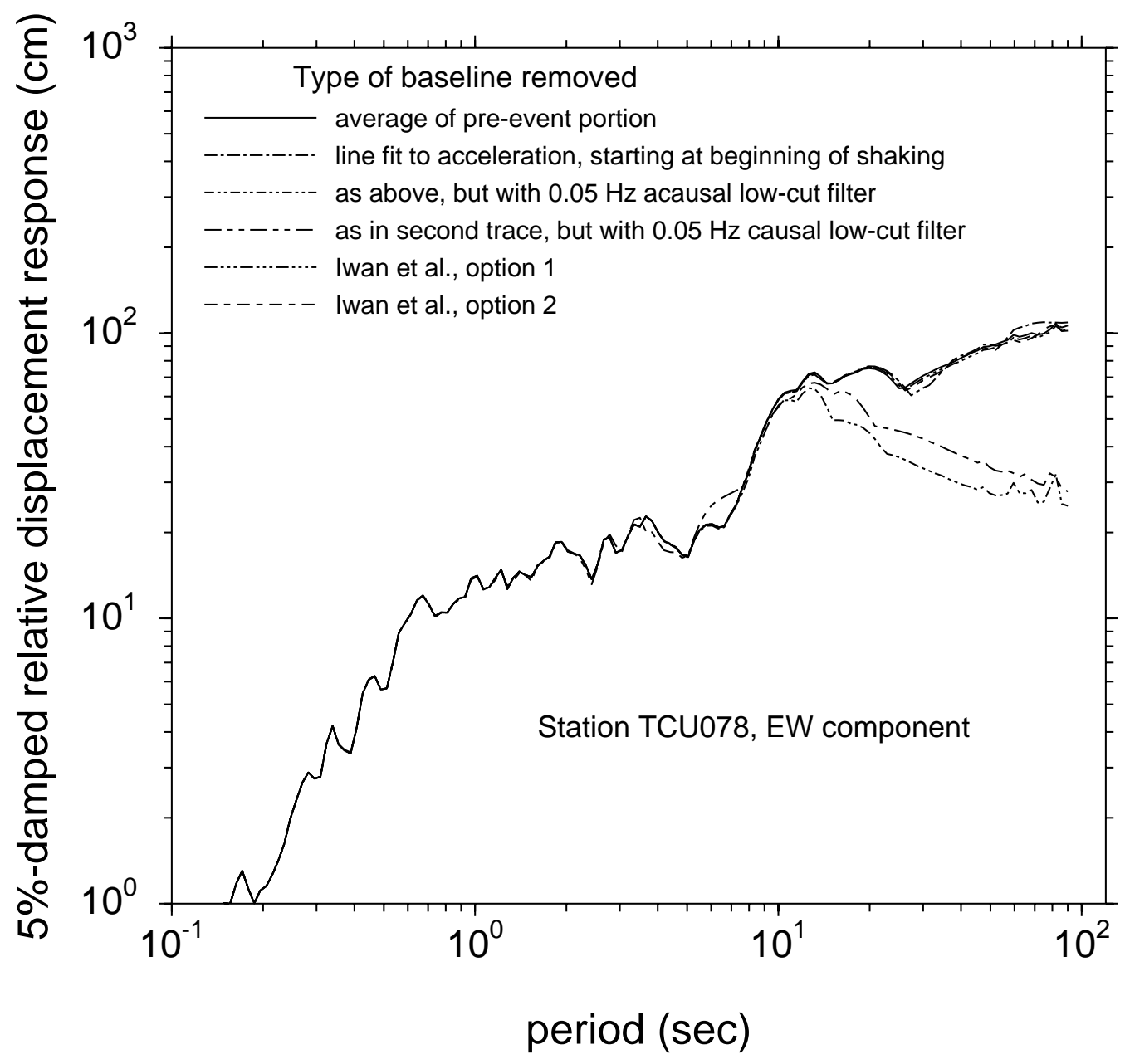

Dec 6, 1999 10:50:47 am

D:IPSVITAIWAN99IT0783_RS.GRA

D:IPSVITAIWAN99IT0783_RS.DT

Figure 24. 5\% -damped response spectra for the accelerations recorded at station TCU078 in the E-W direction, corrected using the baseline-correction schemes considered in this report. 


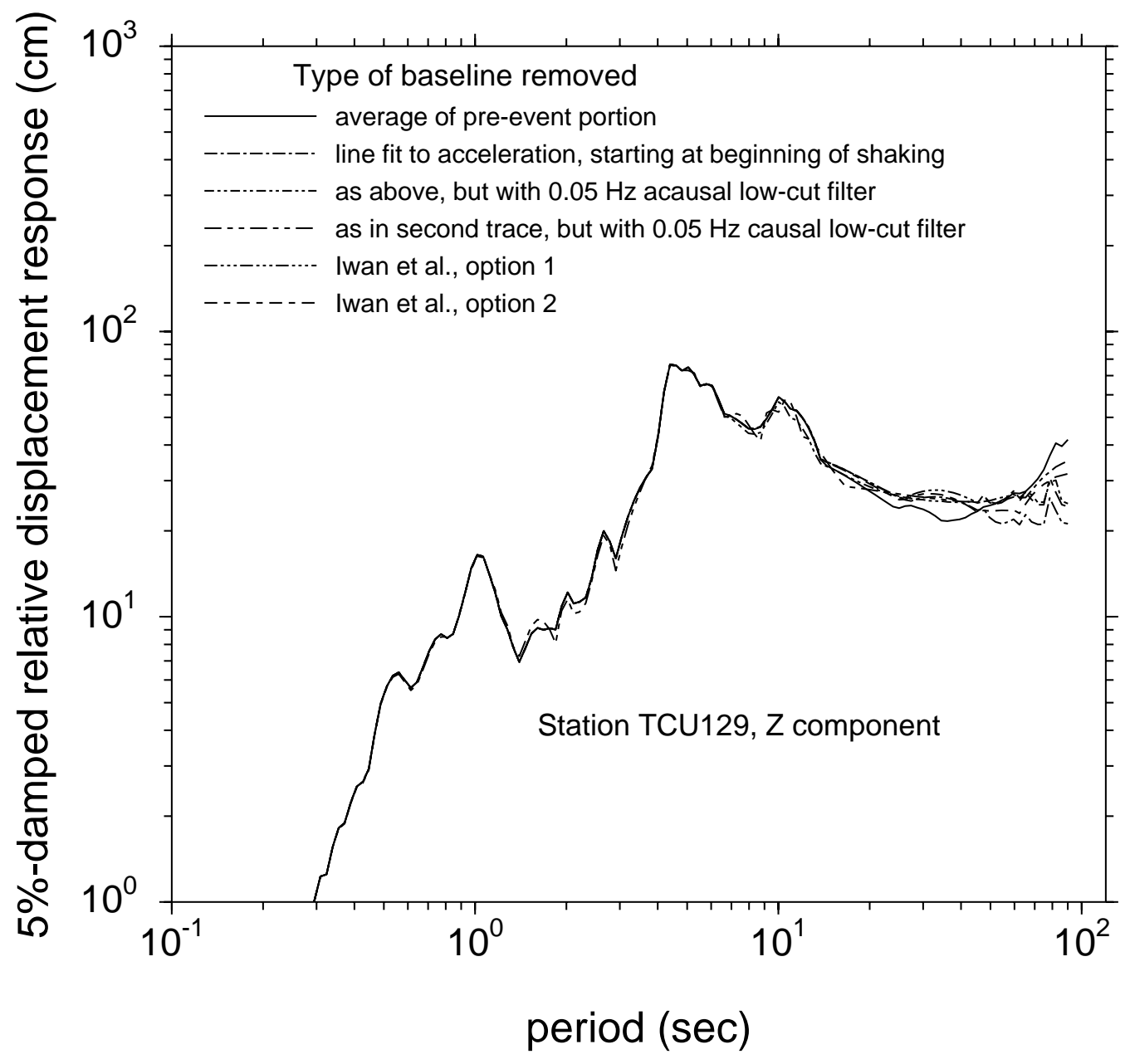

Dec 6, 1999 10:52:48 am

D:IPSVITAIWAN99IT1291_RS.GRA

D:IPSVTAIWAN99IT1291_RS.DT

Figure 25. 5\% -damped response spectra for the accelerations recorded at station TCU129 in the $\mathrm{Z}$ direction, corrected using the baseline-correction schemes considered in this report. 


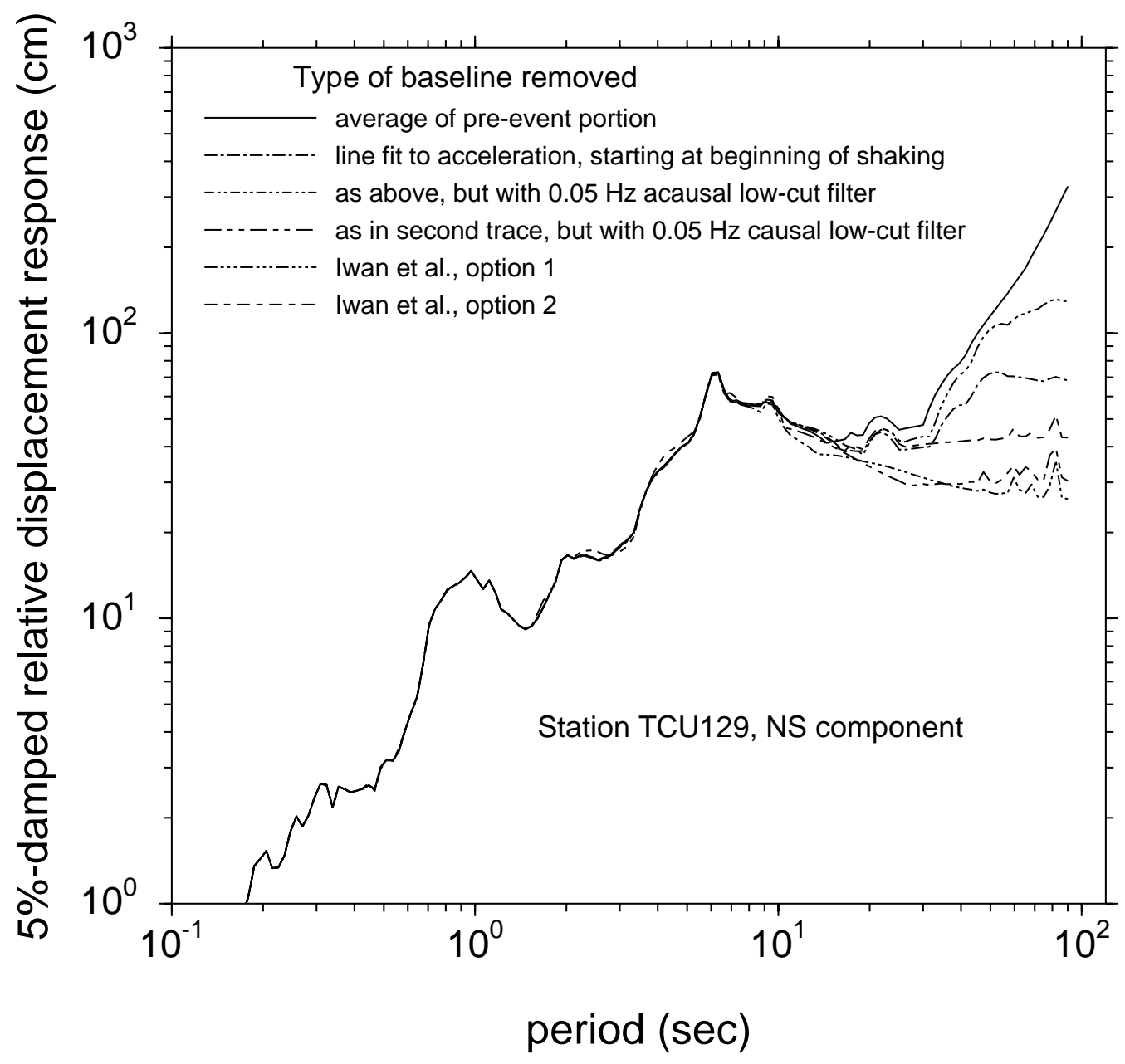

Dec 6, 1999 10:54:16 am D:IPSVITAIWAN99IT1292_RS.GRA D:IPSVTAIWAN99IT1292_RS.DT

Figure 26. 5\% -damped response spectra for the accelerations recorded at station TCU129 in the N-S direction, corrected using the baseline-correction schemes considered in this report. 


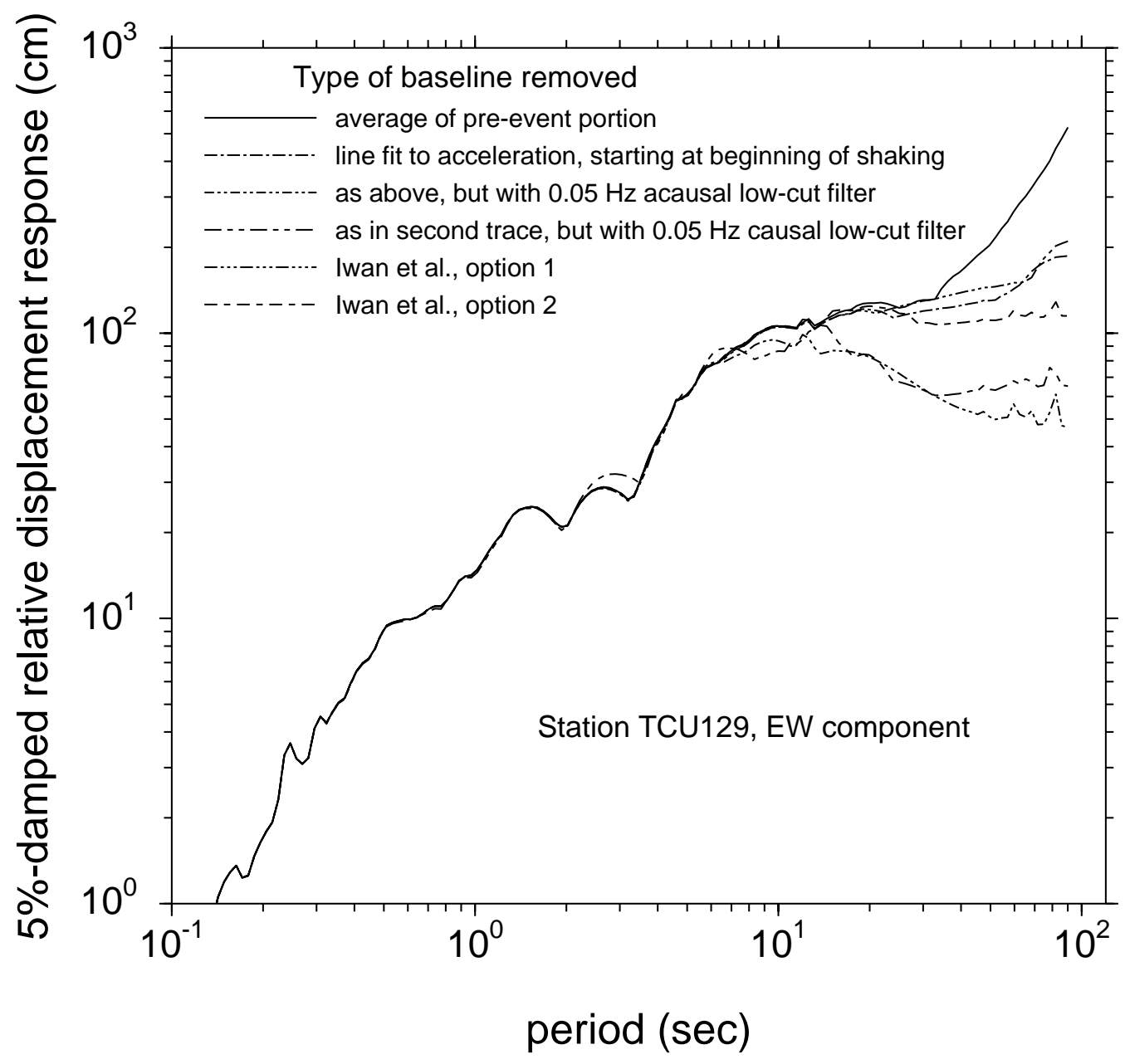

Dec 6, 1999 10:55:07 am D:IPSVITAIWAN99IT1293_RS.GRA D:IPSVITAIWAN99IT1293_RS.DT

Figure 27. 5\% -damped response spectra for the accelerations recorded at station TCU129 in the E-W direction, corrected using the baseline-correction schemes considered in this report. 